\title{
Our Water Mains Contaminate Us with E. Coli, Lead and Copper - Preventable IIIness and Death Follow
}

\author{
Robert Allan Leishear \\ Leishear Engineering, Limited Liability Corporation, Aiken, USA
}

Email address:

leishear@aol.com

To cite this article:

Robert Allan Leishear. Our Water Mains Contaminate Us with E. Coli, Lead and Copper - Preventable Illness and Death Follow. American Journal of Water Science and Engineering. Vol. 7, No. 2, 2021, pp. 72-96. doi: 10.11648/j.ajwse.20210702.15

Received: April 12, 2021; Accepted: April 24, 2021; Published: June 28, 2021

\begin{abstract}
The title of this article may seem abrasive, but the stakes are human lives that are affected by E. coli infections and drinking water contaminations by lead and copper. First of all, this research targets a new and urgent understanding of a common cause for E. coli outbreaks, which results in many illnesses and deaths every year. As part of a world-wide problem, E. coli infects more than 73,000 people and kills more than 60 people every year in the U.S. alone. Also a connection exists between urinary tract infections and water main break transmissions of E. coli, where five to seven million cases strike each year in the U.S. Methods are confined to an extensive literature review and detailed studies of pertinent topics. Research concludes that a phenomenon referred to as water hammer breaks underground water mains, and underground E. coli enters water mains during power outages or pressure losses to distribute E. Coli to our homes, businesses and irrigation systems to drive E. coli outbreaks. People die from E. coli, and illnesses and deaths are preventable. New theory proves that water systems are infected during normal operations that crack water mains to permit E. coli ingress into pipes to infect homes, businesses and irrigation. E. Coli infection outbreaks can be stopped. Essentially, water hammer breaks water mains, E. coli enters piping during power outages and other system shutdowns, infected water is pushed to customers ahead of any disinfectants that are added prior to return to service, and infections spread to water consumers. The most important research conclusion is that E. coli infections will stop by controlling water main break destruction and controlling water operations after power outages and water pressure losses. A parallel health concern relates lead and copper contaminations of water supplies to water hammer induced water main breaks. Another important finding proves that lead and copper contamination of drinking water systems can be minimized. If water hammers are reduced, water main breaks will be reduced, and infections and contaminations will be reduced. Although facts explain observations of lethal E. coli outbreaks, experimental validation of theory following a future outbreak is required. There is more work required, but if people are unaware of this pandemic health hazard, no work will be done, and the hazard will continue. The learning curve to safe drinking water should not climb slowly, but should sharply leap to save lives and ensure water safety.
\end{abstract}

Keywords: E. Coli, Water Hammer, Water Main Breaks, E. coli Outbreaks, Microbiological Ingress, Piping Dynamic Load Factors, Lead and Copper in Drinking Water

\section{Introduction}

\subsection{Significance for Public Health}

New technology addresses E. coli infections, misunderstood E. coli transmission pathways, lead and copper in drinking water, and preventive actions. For water supply safety, minimum chlorine levels control bacteria, but water main leaks introduce untreated water from the soil into the piping to dilute required chlorine concentrations and infect the water supply. Possibilities also exist for inadequate chlorine concentrations and high lead or copper concentrations, particularly in isolated pipe sections that are infrequently used.

Since infrastructure damages due to water hammers that cause water main breaks cost 13 billion dollars per year in the U.S., changes to our drinking water system operations will save hundreds of billions of dollars and more importantly 
ensure safe drinking water. These ideas step to the forefront of technology, a step beyond what others accept to be possible.

\subsection{E. Coli Research and Public Health}

E. coli bacteria, Escherichia coli, are common types of fecal bacteria found in the intestines of animals and humans. For "experimental studies on the survival of the different types of E. coli in soil, manure and water ... the data suggest that E. coli can persist, for varying periods of time, in such terrestrial and aquatic habitats [and can] ... to varying extents, survive in different open environments such as soil, manure and water. ... There are also possibilities for migration between these habitats. For instance, E. coli may reach the groundwater from top soil layers, as revealed in several studies [1]". Also, "fecal indicator species are present at detectable levels in the soil and standing water at main break repair sites [2]". The facts are conclusive that E. coli exists in underground soil, and water main breaks also provide underground water sources for bacteria survival.

The complex processes of E. coli movement in ground water permit soil contamination adjacent to underground pipes. When E. coli are present, migration occurs into cracked pipes following power outages and other pressure losses.

This new research determines that there is a common cause of water system piping contamination by E. coli, and the extrapolation of this new theory to E. coli outbreaks will raise new questions. For example, common beliefs are that contaminations of edible plants result from fecal contaminations of soils by cattle or other animals, but transmission of E. coli from contaminated water to soil and then to cattle is far more plausible than from cattle to soil, since the spontaneous creation of E. coli inside the stomachs of cattle would be required for this latter process, but the processes may cycle, and have been observed to cycle, between soils and hosts. The facts are reasonable, but previous reasoning is questionable. The breadth of applicability for this new theory can only be established by further studies. In short, this research correlates water main breaks to power outages and E. coli infections.

Available theories discuss the mechanics of water main breaks [3, 4], but a new relationship to E. coli emerged through an innovative insight that power outages, and power plant restarts, implement a common cause for temporary E. coli contamination of water systems.

Using this fundamental premise, public records ${ }^{5}$ provide inductive proof of this new theory. Records include E. coli outbreaks documented by the Centers for Disease Control [5], and electrical power outages documented by various sources. By carefully evaluating these sources, a clear relationship between power outages, water main breaks, and E. coli infections becomes apparent. In other words, the technical data was available, but a theory to connect the outbreaks has only recently been discovered.

\subsection{E. Coli Research Methods}

This specific research on E. coli infections was completed during February through April of 2021. Even so, this research was but one part of ongoing voluntary research. This specific research was based on literature reviews of $\mathrm{E}$. coli contaminations, but a clear understanding of water main breaks stretches back to the early 1990s, where extensive studies and computer models clearly demonstrated the primary, common-cause failure mechanism for piping systems, i.e. water hammer breaks water mains. With decades of research in hand, an E. coli investigation is a natural outcome of ongoing research into the worldwide fluid transient disaster.

That is, decades of research provided the tools to interpret $\mathrm{E}$. coli infection data that has been previously overlooked and misunderstood. New research explains the complex physics of water distribution systems with respect to the spread of E. coli infections. Consequently, this ground breaking research is an essential step toward the prevention of E. coli outbreaks and resultant illness and death. Public awareness through this publication and the resultant education of the public are mandatory requirements to stop E. coli.

\subsection{Lead and Copper in Drinking Water}

Furthermore, water hammer accelerates corrosion of lead and copper in water systems. Water hammer theory to explain water main cracks and corrosion was available prior to this study. Control of water hammers will minimize contaminations. E. coli infections are discussed first at some length, followed by a brief discussion of lead and copper contamination of water supplies. Severe health hazards mandate public awareness.

\section{The Evolution of a New Theory to Stop E. Coli Infections}

\subsection{E. Coli and Water Main Breaks}

Elegantly simple yet extraordinarily complicated new theory threads together E. coli outbreaks that occurred for more than a century in myriad locations. The elegantly simple route of the disease infects us through our water supplies. However, the infection process extraordinarily complicates the spread of this lethal illness, where E. coli exists in the soil at different locations.

A process known as water hammer sends shock waves through piping systems to crack the piping, these cracks grow through repeated hammers or corrosion that initiates in the crevices of crack sites, and water hammer cracks nearly all of the 237,600 yearly water main breaks in the U.S. Each year, there is one break in every 3.7 mile long section of the United States water main system, which includes 880,000 miles of piping [4]. Similar breaks occur in every industrialized community worldwide. Power outages or water system shutdowns lower the pressures in the water supply piping to induce infections.

When pressures lower, E. coli migrates into piping systems to grow until the water pressure is turned back on. When the water pressure increases, E. coli flows to our restaurants, businesses, homes and irrigation systems for our farms and 
ranches, i.e., infected water in the offending system flows to end-users. Even when piping systems are partially disinfected with high concentrations of chlorine at some local point in the system [6], contaminated water downstream of the disinfection location still introduces infected water to the end-user, since de-pressurizations are not effectively controlled with respect to E. coli ingress into pipes.

\subsection{The Facts Obscure Subsequent Investigations}

Also when investigations are later performed, infected water is completely flushed from the pipes to wash away the evidence of E. coli contamination. The flushing of water mains introduces many pipe volumes of water to far exceed the water required to remove all contaminants before inspections are performed as part of E. coli investigations. That is, when an inspection is performed, all of the E. coli evidence is washed from the water supply, and a quick and incorrect conclusion improperly deduces that $\mathrm{E}$. coli is absent from the water supply, which actually caused contamination and infections. In other words, complex processes affect not only the distribution of an infection but affect the detection of infection distribution sources.

\subsection{The Scope of the Problem: Epidemic Versus Pandemic}

In view of the following definitions, this problem of E. coli infections originated by water main breaks constitutes an epidemic for each specific outbreak, and the overall worldwide presence of infection constitutes a pandemic.

As defined by the U.S. Centers for Disease Control, "Occasionally, the amount of disease in a community rises above the expected level. Epidemic refers to an increase, often sudden, in the number of cases of a disease above what is normally expected in that population in that area. Outbreak carries the same definition of epidemic, but is often used for a more limited geographic area. Cluster refers to an aggregation of cases grouped in place and time that are suspected to be greater than the number expected, even though the expected number may not be known. Pandemic refers to an epidemic that has spread over several countries or continents, usually affecting a large number of people.

Epidemics occur when an agent and susceptible hosts are present in adequate numbers, and the agent can be effectively conveyed from a source to the susceptible hosts. More specifically, an epidemic may result from:

1) A recent increase in amount or virulence of the agent,

2) The recent introduction of the agent into a setting where it has not been before,

3) An enhanced mode of transmission so that more susceptible persons are exposed,

4) A change in the susceptibility of the host response to the agent, and/or

5) Factors that increase host exposure or involve introduction through new portals of entry..."

\subsection{A Common Cause of Water Main Breaks}

To understand E. Coli ingress into piping systems, the common mode mechanism of water hammer cracking of water mains needs consideration. During pump and valve operations, high pressure shock waves travel at thousands of feet per second throughout piping systems to crack pipes, and these shock waves may crack pipes miles away from the pumps or valves that cause leaks. Repeated hammers increase crack sizes, and corrosion further increases crack sizes.

First published in 2001, the Leishear Stress Theory describes how and why pipes fail when subjected to water hammer. Recently, this theory was applied to explain water main breaks. This theory explains water main breaks by applying a concept of dynamic load factors (DLFs) to describe equivalent loads to rupture or crack water mains.

For example, a common 200 pound per square inch pressure wave from a water hammer can have an equivalent effect of nearly 800 pounds per square inch. That is, the DLF is less than four for the circumferential hoop stress, which is the primary failure stress for water mains. Such pressure waves induce fatigue failures after many cycles, and crevice corrosion forms in these cracks to accelerate water main failures. Near the end of dead end pipes, the DLF can be increased to nearly five due to wave reflection processes. Also, the DLF is less than 2 for the loads exerted on bends, and the circumferential loads exerted on valves. DLFs are further complicated by the fact that as loads increase, the DLF approaches 1 due to exceedingly high damping during plastic deformation. All of these high values for DLFs are applicable to systems with suddenly closed valves. As the valve closure rate decreases, the DLFs approach one in all cases [3, 4, 7]. There are different methods to control water hammers, but slowing down the valve closure rates and pump startups and shutdowns are quite effective in reducing piping cracks.

Extended pressure losses induced by water hammers explain E. coli influx into the piping and E. coli transmission to customers. Pipes crack anywhere, and the number of cracks in any given pipe increases over time. Since underground water mains follow the terrain, lower pressures near hilltops provide the most likely location for E. coli ingress during pressure losses.

\section{Ongoing Spread of E. Coli Infections}

\subsection{Fatal Intestinal E. Coli Outbreaks and Infections}

Before specifically interrelating E. coli infections to water main breaks, the spread and types of infections require introduction. E. coli outbreaks result in various disease symptoms. More sudden disease symptoms occur during outbreaks, but other symptoms occur between outbreaks.

During outbreaks, common symptoms include stomach problems during infection outbreaks. "Escherichia coli (E. coli) bacteria normally live in the intestines of healthy people and animals. Most types of E. coli are harmless or cause relatively brief diarrhea [8]. But a few strains, such as E. coli O157:H7, can cause severe stomach cramps, bloody diarrhea and vomiting... Signs and symptoms of E. coli O157:H7 infections usually begin three or four days after exposure to 
the bacteria. But you may become ill as soon as one day after exposure to more than a week later".

\subsection{Urinary Tract E. Coli Infections}

Between major outbreaks, less sudden forms of E. coli cause "a urinary tract infection when germs (bacteria) invade the urinary tract. The urinary tract is made up of your kidneys, bladder, ureters, and urethra. The ureters are the tubes connecting the kidneys to the bladder [9]. The urethra is the tube carrying urine from the bladder to outside your body. According to the National Kidney Foundation, 80 to 90 percent of urinary tract infections are caused by bacteria called E. coli. For the most part, E. coli lives harmlessly in your gut. But it can cause problems if it enters your urinary system, usually from stool that migrates into the urethra. Urinary tract infections are incredibly common. In fact, 6 to 8 million cases are diagnosed each year in the United States [That is, approximately 5 to 7 million cases per year are attributed to E. coli]. ... While men aren't immune, women are 30 times more likely to develop symptoms, mostly because of the design of their urinary tract", such that women are infected via their own stool. Water main break contaminations of drinking water may contribute to kidney infections, but the full scope of this aspect of E. coli infections needs further investigation. Even so, distribution through water main break processes is the probable cause for E. coli urinary tract infections.

\subsection{Water Source Contaminations}

The fact is that many water sources are contaminated, and water treatment inhibits most contaminations from reaching drinking water. In fact, "The presence of Escherichia coli in water is used as an indicator of fecal contamination, but recent reports indicate that soil populations can also be detected in tropical, subtropical, and some temperate environments [10]. ... Viable E. coli populations were repeatedly isolated from northern temperate soils in three Lake Superior watersheds from October 2003 to October 2004. Seasonal variation in the population density of soil borne E. coli was observed; the greatest cell densities ... in the summer to fall (June to October), and the lowest numbers ... occurred during the winter to spring months (February to May)". In general, water source contamination is controlled through disinfection at water treatment plants, but the new infection route cited here is currently uncontrolled.

\subsection{Drinking Water Contamination and Disinfection}

Since potential contaminations of water supplies have long been known, legislation requires that chemical disinfection must be performed when large water main breaks occur or when water mains are opened for repairs. In fact, failure to perform such disinfection may result in both criminal and civil liabilities.

For example, "An outbreak of hemorrhagic E. coli serotype 0157:H7 occurred in Cabool, MO during December 1989 and January 1990 and resulted in 240 cases of diarrhea and 4 deaths... It was concluded that the illness was caused by waterborne contaminants that entered the distribution system through two major pipe breaks and 43 service meter failures that occurred during unusually cold weather.... The water utility did not practice disinfection following main repairs, relying instead on flushing the repaired main with finished water" [2]. However, water mains are typically disinfected.

How then can E. coli frequently contaminate water supplies? During a power loss, leak sites throughout the water system potentially permit excessive quantities of E. coli to ingress into pipes, where ingress is governed by numerous parameters, i.e., size of the breaks, water temperatures, localized pressure at the breaks, presence or absence of E. coli in the soil, and concentration of E. coli near the breaks.

Verified by field tests, $50 \%$ of soils are contaminated by fecal bacteria, and tests proved that contaminants enter pipes during pressure losses $[11,12]$. Once cracks form, lowered piping pressures permit E. coli in the surrounding soil to enter pipes, where electrically powered pumps typically supply operating water pressures.

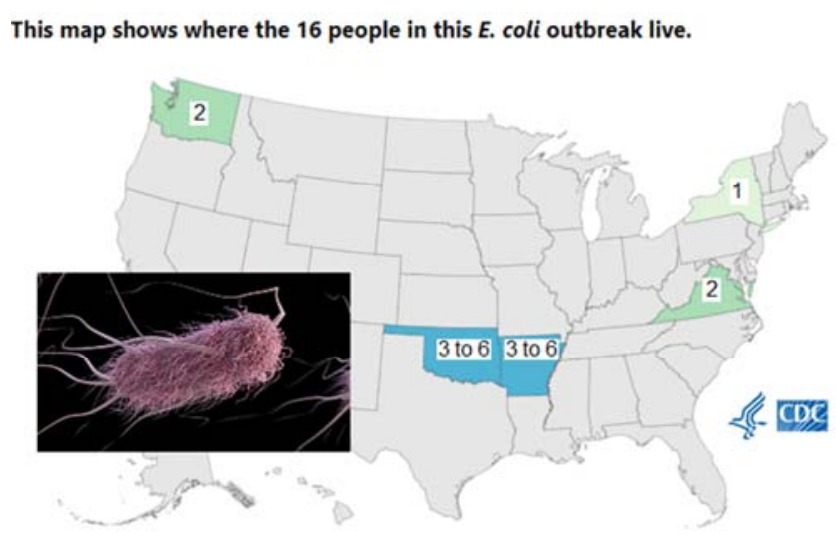

Figure 1. 2021 Outbreak Map of E. Coli Infections as of February 2, 2021 [5].

\subsection{E. Coli Contaminations and Disinfection}

To arrest contaminations, disinfectants referred to as chlorine spikes are added to piping, but chemicals are not effective for the E. Coli source considered here. Although these disinfectants are very effective as they flow through the pipes, disinfectants cannot control infected waters ahead of, or downstream of, the flowing disinfectant. That is, E. coli migrates into the pipes ahead of the added disinfectant, and E. coli is then pushed forward, ahead of the cure, to dispense and potentially infect end-users.

This short-term infection process is further complicated by the end use at the time of infection. If infected water is not directly applied to produce or other food items before the infected water is exhausted, a local outbreak fails to occur. To get sick, food items must be exposed to E. coli. For example, a common practice to prevent the spread of infections is to wash hands, but if the water supply is temporarily infected, washing soap from the hands can re-infect the hands that were just washed. Disinfectants are preferred for hand cleaning.

In other words, leaks to contaminate piping systems with $\mathrm{E}$. coli occur randomly, and the possibilities of infections are 
random. Even so, infections of food products at a distribution source such as a farm for leafy vegetables or packing plants for meats or flour spread E. coli infections over multiple states. This apparent non-random distribution of E. coli infections for foods shielded the current discovery of a common cause of infections for decades. Although infections are random, the causes of those infections are not so random, where water systems are to blame for E. coli outbreaks.

\section{E. Coli Ingress into Water Mains}

\subsection{E. Coli Outbreak Observations}

Outbreaks initiate from many identified causes, which include meat processing, flour, leafy greens and vegetables. Each of these products may be tainted by an infected water supply during handling by employees if they are unknowingly infected by an infected water supply, and product recalls occur. Hence, the need is compounded to further evaluate water main breaks and contamination. Unfortunately the time when products are contaminated is frequently unclear, and locations and times for outbreaks are extraordinarily unpredictable. From the results of this study, power outages and extended shutdowns initiate infections.

\subsection{Power Outages and E. Coli Infections of Water Mains}

Although tracing food contamination to a specific power outage is extremely difficult after the fact, a relationship between specific power outages and contamination must be undertaken during a future E. coli infection outbreak, where local power outages affect specific locales to contaminate specific products.

Note that power outages occur nearly every day in the United States, and major outages due to storms may also contaminate water mains. The full extent and sweeping effects of this new discovery can only be discerned through future research, but the dangers due to illness and death are substantial as shown in Figure 3, where yearly averages for investigated major outbreaks represent a fraction of yearly infections. Between January 1, 2012 and February 2, 2021 in the United States, reports concluded that major outbreaks infected 1288 people, hospitalized 421 people, and killed 10 people due to E. coli. Nationwide every year, E. coli infects more than 73,480, hospitalizes 2168 , and kills 61 . The transmission routes are: $52 \%$ - foodborne; $21 \%$ - unknown, $14 \%$ - person to person; $9 \%$ - water borne; $3 \%$ - animal contact; and $0.3 \%$ - laboratory [13]. The Centers for Disease Control identified these specific causes but failed to identify specific pathways that initiated these infections. Contaminated water supplies potentially spread nearly all infections, and immediate actions will curtail this tragedy. Yes, there is uncertainty with infection predictions, but the facts clearly indicate that water hammer breaks water mains to permit $\mathrm{E}$. coli ingress to cause illness and death.

\subsection{Power Outages and E. Coli-An Example}

Now consider a specific recent example of E. coli infections and related power outages. Power outages occurred across the United States between December 20 and December 21, 2020.

According to the Centers for Disease Control, symptoms appear 2 to 18 days after exposure with a 3 to 4 day average, and an association, or connection, between an infected person and a specific outbreak frequently requires 2 to 4 weeks. In other words, the recorded infections occurred within the 28 day window between initial exposures and onset of symptoms, as discerned from Figures 1 and 2. An unknown food source was prescribed as the outbreak cause, and no deaths occurred during this outbreak [5]. This example provides partial inductive proof of theory.

This chart shows when the 16 people in this E. coli outbreak got sick. Recent illnesses may not yet be reported as it usually takes 2 to 4 weeks to link illnesses to an outbreak.

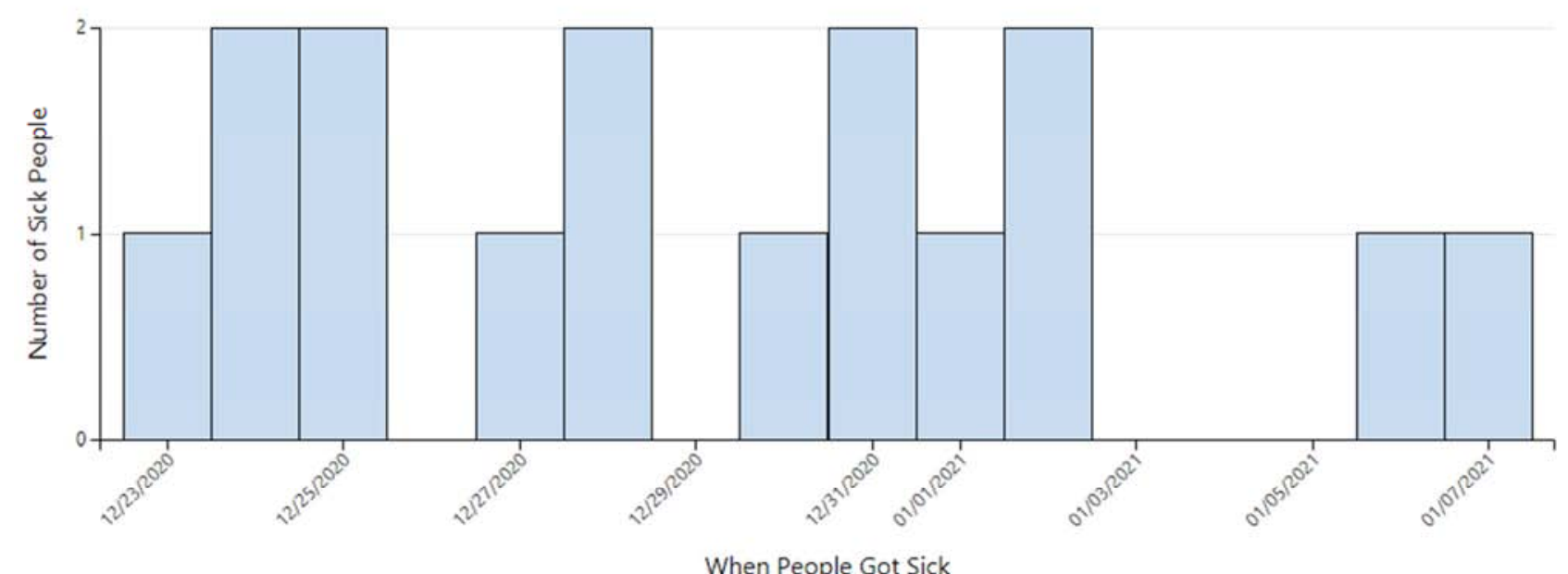

Figure 2. 2021 E. Coli Outbreak Illness Dates as of February 2, 2021 [5]. 


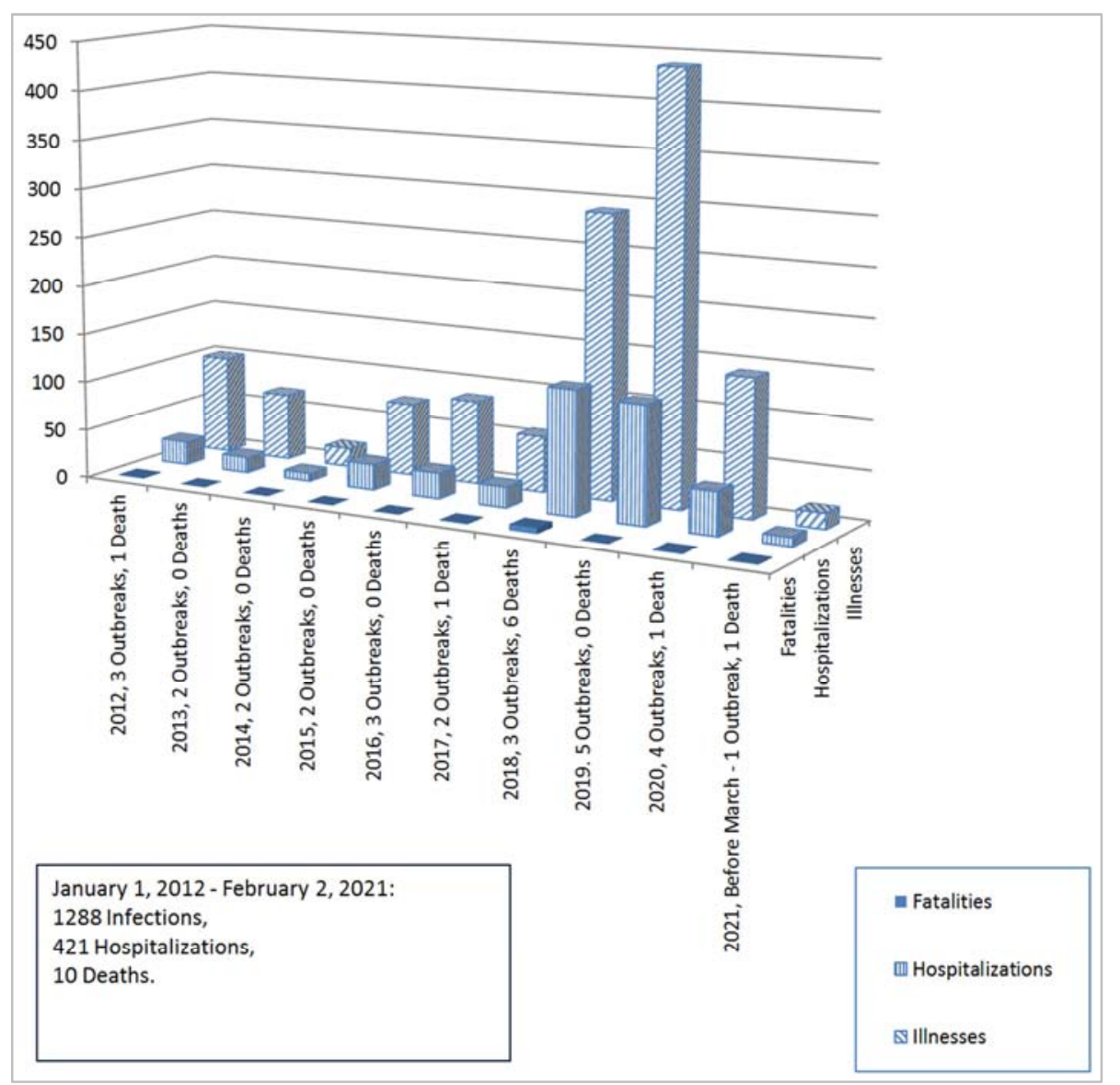

Figure 3. Major Outbreaks: E. Coli Infections, Hospitalizations and Deaths (Plotted from U.S. Centers for Disease Control Data [5]).

\subsection{Power Outages and E. Coli-Another Example}

Another example better explains the uncertainties associated with this new theory. From Figure 3, one gleans that the worst year for E. coli infections was 2019, and Figure 4 displays results for the worst of five outbreaks that year. The Centers for Disease Control reported that there were 209 cases, 29 hospitalizations, and zero deaths across 10 states [14].

Through interviews, investigators concluded that $79 \%$ of the people infected consumed ground beef, and all ground beef tested negative with two exceptions. One Tennessee restaurant possessed ground beef with the specific strain associated with this outbreak, and a different E. coli strain was found in one Kentucky institution. More than 160,000 pounds of potentially contaminated raw ground beef were recalled by distributors in Illinois (53,200 pounds) and Georgia (113,424 pounds), and no single distributor was isolated as the outbreak cause.

A local power outage occurred in Georgia on March 7, 2019, which is consistent with the theory presented here. A local power outage also occurred in Illinois on March 27, 2019 [15, 16], and this date occurred after the infection started. According to the new theory, infections started in the raw beef processing plants operated in Georgia.

This example provides inductive proof of the new theory for E. coli transmission. The inductive logic steps are as follows.

1. All water mains randomly crack due to water hammer.
2. A power outage occurred prior to infections.

3. E. coli ingresses into water main cracks during power outages.

4. E. Coli was transmitted through water main systems that were subjected to a power outage.

5. E. coli was found in an area subjected to a power outage.

6. Therefore, water main breaks caused E. coli infections.

This new theory provides a new investigative tool. When an outbreak occurs, look to the power outage maps and water system outages for the cause of the infections. Even so, additional investigation will be required to establish absolute certainty for conclusions.

\subsection{Research Limitations}

The greatest limitation to E. coli infection research is that while this work is based on facts, competent research is still theoretical, and field research must be performed to cement this theory into fact to effectively convince others of the validity of this new theory. Although this author is quite certain of this new theory, experimental validation will push this research forward.

Specifically, when an outbreak occurs following a power outage or loss of pressure due to another cause, a shutdown and re-pressurization needs to be repeated immediately after the outage to duplicate the infectious conditions that occurred during an outage. Other causes of pressure loss can be as simple as a pressure loss through water leaks or prolonged isolation of a piping section. Of particular interest, leaks may occur more 
frequently near hilltops, since water mains follow the terrain, and the lowest system pressures occur at higher elevations.

Since entire cities cannot be isolated for testing after re-pressurization, the judicious choice for retest and E. coli validation will be difficult indeed. Additionally, disinfection using high chlorine concentration spikes can force highly chlorinated water through piping cracks to the outside of the pipe to retard growth or kill E. coli bacteria. That is, the E. coli infection processes are extremely complex, and further studies of the transmission mechanisms are required. Even so, this author believes that there are no doubts about the importance and validity of this new theory.

\section{An Opposing Point of View}

\subsection{An Alternate Theory for Microorganism Ingress}

An alternate theory to the work presented here is that low pressures during momentary water hammers result in the ingress of microorganisms into water mains [17]. This author disagrees, and believes that extended power outages and extended pressure losses result in E. coli ingress, where water main pressure transients initially damage water mains to permit E. coli ingress in the first place. The spread of infection is far more complicated than previously believed, and this now corrected lack of insight delayed an understanding of $\mathrm{E}$. coli infections.

To explain the alternate theory, when water hammer occurs there are momentary pressure fluctuations about the operating pressure. Operating pressures are typically designed above 60 to 70 pounds per square inch to provide adequate pressures to end-users. Pressure fluctuations due to water hammers frequently vary between 200 to 300 pounds per square inch for half of the time, and the pressures are negative when vacuum pressures exist for the other half of the time. This alternate theory assumes that micro-organisms ingress into water mains during these short term vacuum pressure excursions (seconds to minutes).

\subsection{A Rebuttal to an Alternate E. Coli Theory}

To counter with this opinion, consider that as water leaks from water mains, higher pressures will subsequently force $\mathrm{E}$. Coli away from pipes at much higher egress rates than the returning vacuum pressure ingress rates. That is, E. coli bulk flow moves away from pipes as water flows from leaks. Even so, there is a potential contamination route due to leak sites on pipes. For this contamination theory, jets of water spurt from the pipes during high pressures, and surrounding, minimally disturbed, contaminated water would, according to this alternate theory, entrain through the pipes at the leak site during the vacuum ingress half-cycle. However, if such a process occurred, the cycle would be frequently repeated, and E. coli would be detected during routine inspections following outbreaks, which does not occur except for specific cases where infection causes are easily identified. This typical observation dissuades a conclusion that ingress occurs only during short term transients. The new theory promoted here depends solely on the motion of E. coli into pipes while systems are shut down for long periods of time (hours to days), and the past inability to identify infection causes further supports the theory presented here.

Having written a book on water hammer and piping failure analysis, this author has a good understanding of fluid flows during transient pressures and failure mechanics of water mains. This author also served as a published expert on mixing processes, corrosion and fluid jets. E. Coli movements encounter each of these processes during pipe leaks at the soil interface.

\subsection{Rebuttals to Alternate Water Main Break Theories}

Additionally, this author disagrees with other proposed causes of water main breaks [15]. Although the cited causes of soil stresses and corrosion are contributing causes to water main breaks, water hammer is the common cause as proven in publications $[3,4,7]$, which in turn were based on hundreds of other references and many years of research. For example, ground shift due to winter temperatures was cited as a cause of piping cracks due to soil stresses, but this author contends that the possibility approaches zero to crack an underground metal pipe when concrete roads above that pipe do no crack. Also as noted, cracks accelerate corrosion, but corrosion alone seldom initiates water main breaks.

\section{Parallel Drinking Water Safety Problems}

\subsection{Chemical Permeations}

Chemical permeations, primarily from organic gasoline products, are a contamination problem in water main systems, typically identified by users due to taste and smell. Specifically, underground chemical contaminants permeate through pipe walls and gaskets to contaminate drinking water.

Permeation, while an important health hazard, occurs far less frequently than water main breaks. For example, permeation events per million miles of water mains per year, includes 1 event for metallic pipes, 3 events for concrete-asbestos pipes, and 46 events for plastic pipes [18]. This new use of plastic piping causes new problems.

Since corrosion has been incorrectly believed to be the cause of water main breaks for more than a century, plastic piping has become popular as a replacement for metal pipes. As noted in other work $[3,4,7]$, plastic water mains break due to water hammer, just like metallic pipes, which permits seepage of ground chemicals into drinking water systems through leaks as well. In other words, plastic pipes do not solve the problem of cracked water mains, but introduce new contamination problems as well.

\subsection{A New Theory to Minimize Lead and Copper Leaching}

Chemical leaching occurs when lead and copper leach from pipes into water systems. In addition to stagnant flows in piping, $\mathrm{pH}$, alkalinity, and dissolved inorganic ions are primary contributors to lead and copper corrosion that forms contamination. Chemical treatments are available to control 
leaching. Water hammers accelerate copper and lead corrosion rates to accelerate leaching.

More importantly, dynamic load factors effectively multiply the pressures that are caused by water hammers, and pipe stresses increase in the walls of water mains. At higher stresses, there are two important failure mechanisms. First, repeated hammer cycles crack pipes, which were considered by the Leishear Stress Theory. Second, higher stresses accelerate localized corrosion even in the absence of cracks, which is a long known fact in the corrosion industry, but the fact that water hammer causes such stresses is also expressed by the Leishear Stress Theory. Water hammer breaks water mains, all piping construction materials are cracked by water hammer, and water hammer accelerates corrosion both at crack sites and at other highly stressed areas of the piping.

In other words, leaching is affected by basic corrosion mechanisms as well as high stresses due to water hammers. This conclusion is remarkably important since there is much work in progress to remove lead and copper from water systems, and the effects of stresses on lead and copper leaching are not presently under consideration by government agencies. The relative influence of water hammer versus corrosion is undetermined at this point in time, and further research is recommended. Even so, preventing water hammers until contaminating pipes are replaced will improve drinking water quality and public safety.

\subsection{Health Effects from Lead Leaching}

To emphasize the importance of this research, the health effects of lead and copper in drinking water bear scrutiny. Severe cases of copper poisoning have led to anemia, liver poisoning, and kidney failure.

For children, "even low levels of lead in the blood of children can result in: Behavior and learning problems; Lower IQ and hyperactivity; Slowed growth; Hearing problems;
Anemia; and in rare cases, ingestion of lead can cause seizures, coma and even death.

For pregnant women, Lead can accumulate in our bodies over time, and can result in serious effects to the mother and her developing fetus, including: Reduced growth of the fetus; and Premature birth.

Adults exposed to lead can suffer from: Cardiovascular effects, increased blood pressure and incidence of hypertension; Decreased kidney function; and Reproductive problems (in both men and women)" [19].

\section{Prevention - The Next Steps}

\subsection{Water Hammer Control}

The primary mechanism endorsed here to prevent E. coli infections and control leaching is to prevent water hammer and resultant water main breaks. If water main breaks are stopped, ingress of E. coli into water mains and consequent infections will stop as well. If water hammer is stopped, leaching will be minimized.

Water main breaks are presently controlled through various techniques. Water hammer is the primary cause of water main breaks, even though corrosion has been incorrectly assumed to be the primary cause of water main failures for more than a century.

Nearly all cracks in water mains may be eliminated through water hammer control. These controls include various techniques, which include control of valve closure speeds, fire hydrant closure speeds and pump speed controls. Equipment and training costs are the hurdle to be jumped to stop water main breaks, but since there is an expected trillion dollars in repair costs over the next 25 years, perhaps this hurdle can be broached. And, since water main cracks represent a public health hazard due to E. coli transmissions and lead and copper poisoning, these new facts prevail as reasons to leap over this hurdle.

\section{People infected with the outbreak strain of E. coli 0103}

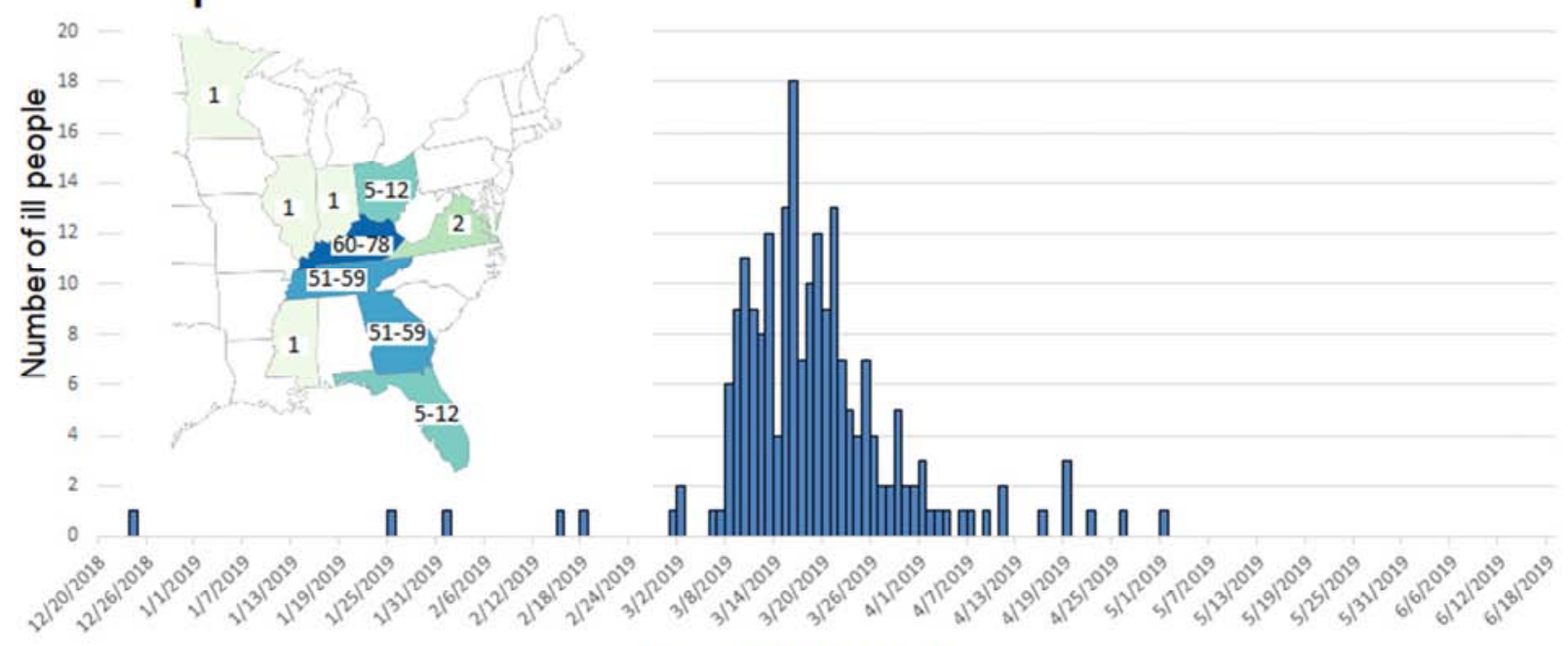

Date of Illness Onset

Figure 4. 2019 E. Coli Outbreak Map and Illness Dates [5]. 


\subsection{Corrosion Control}

For control of internal corrosion of pipes, chemical inhibitors minimize water main leaks through the use of different chemical additives to drinking water, e.g., silicates, polyphosphate-zincs and orthophosphates [20].

For control of external corrosion of pipes, cathodic protection is sometimes used. Corrosion, or rust for steel and iron pipes, is an electro-chemical process that releases corrosion products into the water due to an electric current flow from the pipe into the water. For example, cathodic protection prevents rust in water tanks by using aluminum and magnesium blocks, or anodes, to corrode instead of the steel. Periodically replaced, these materials disintegrate due to corrosion, as electric current flows from the metallic anode in the direction opposite to the corrosion current. When the corrosion current is completely overcome by this opposing current, corrosion is arrested, i.e., the corrosion current becomes equal in both directions and corrosion stops.

Alternatively, cathodic protection may be provided by electrical sources. For piping, these sources are external to the pipes, and multiple sources are placed along the pipes. This cathodic protection process acts similar to metallic anodes, except that the power is supplied by an electric power source to oppose corrosion current and stop corrosion. Magnesium anodes may be spaced along pipes as well.

Each of these processes affords some protection to water mains to minimize corrosion. However, none of these methods arrests corrosion completely, since only 30 percent of water main breaks are caused by corrosion. Only in the past couple of years has water hammer been identified as the primary cause of water main breaks.

\subsection{E. Coli Contamination Control}

Can all E. coli infections be stopped by controlling water main failures and resultant E. coli distributions? Perhaps not, since all of our water supply systems are affected, but the more work that is performed to stop this cause of illness and death, the less that illness and death will occur. Other actions for water distribution may be taken as well. For example, completely purging water systems before use - after depressurization and chlorination spikes - would be beneficial for E. coli prevention, but such purging after every outage is impractical.

There may be much work required, but a path to minimize $\mathrm{E}$ coli illnesses and fatalities is now available. This new understanding of E. coli transmission needs to be urgently addressed by public officials. A remaining unanswered question is exactly how much infection control can be provided? Since these research results are brand new, the subject of E. coli control and transmission will ask more questions if and when actions are taken to stop E. coli outbreaks. Current practices address E. coli infections after arrival, and new technology affords an opportunity to preemptively strike E. coli infections before infections occur.

\subsection{Lead and Copper Contamination Control}

Can all leaching be stopped by controlling water hammers? Probably not since some leaching is caused by corrosion alone. For example, investigations of the Flint River lead contamination of drinking water recognized corrosion as the primary problem, but the effects of water hammer on corrosion acceleration was not considered at all.

Can leaching be minimized significantly? Certainly, but the full extent of leaching control through water hammer control can only be determined through implementation. Any actions taken to reduce water hammer damages to water mains will improve public health by reducing contaminants.

For example, the current practice of replacing municipal water mains without replacing water mains to homes or businesses may be problematic. Some cities replace both parts of the system, some cities do not, and homeowners or businesses are responsible for part of the system replacement.

The facts are well known in the corrosion industry that this type of partial replacement results in lead contaminations of homes and businesses. Construction practices have been blamed for resultant lead contamination, but replacement of the water main piping alone may be the actual cause of lead pipe service lines to homes.

Specifically, if plastic piping replaces the main and the service remains as lead piping, reflected and transmitted pressure waves will occur at the intersection of the two different pipe materials, e.g. plastic and lead. Consequent transmitted stresses in the lead piping can induce cracks and corrosion. Details of such calculations are recommended and are outside the scope of this paper, since piping dimensions and replacement materials vary from system to system.

Those companies responsible for installations of such tie-ins are responsible for water hammer design calculations. Even so, this health concern is not addressed in current practice with respect to reflected pressure waves and consequent dynamic stresses, and public health is affected. This comment is based on extensive experience with practicing engineers and extensive research. For example, an Associate Editor of a different journal essentially commented that all water hammer problems have been solved by industry, i.e., suggested solutions "avoid water hammer, which is pretty typical operations". Such a suggestion ignores the problem of water hammer and dynamic stresses.

Since the premises of this paper are not universally accepted yet, solutions may not be implemented in many cases. Overall, the scope of this problem and solution are presently unknown since resistance to new ideas is a monumental hill to climb. People, even professional, do not like new ideas and change.

\section{Public Health Implications and Ethics}

\subsection{Public Health Effects}

This new technology questions earlier understandings of E. 
coli infections and leaching. On the one hand, does E. Coli originate in the intestines of animals and humans? On the other hand, does E. coli originate in the water mains that supply drinking water for animals and water for crops? This second question has been partially answered. Water main breaks supply contaminated water to plants and animals, and water main breaks can be stopped. Public health implications are obvious, death and illness can be prevented. Additionally, leaching of poisonous lead and copper metals into drinking water can be minimized.

\subsection{Ethics}

Ethics [21] demand that this new theory be printed and that actions be taken.

1) "Everyone has the right to a standard of living adequate for the health and well-being of himself and his family".

2) "New collaborations will be needed to rise to new public health challenges".

3) "Because fundamental social structures affect many aspects of health, addressing the fundamental causes rather than more proximal causes is more truly preventive".

4) "The full range of scientific tools, including both quantitative and qualitative methods, and collaboration among the sciences is needed".

5) "Public health should seek to translate available information into timely action".

6) "In many instances, action is required in the absence of all the information one would like. In other instances, policies are demanded by the fundamental value and dignity of each human being, even if implementing them is not calculated to be optimally efficient or cost-beneficial".

7) "The mandate to assure and protect the health of the public is an inherently moral one. It carries with it an obligation to care for the well-being of others and it implies the possession of an element of power in order to carry out the mandate".

These various tenets of ethics in the health industry demonstrate the public health and moral obligations to act on the relationships between water main breaks, and E. coli illnesses and deaths, as well as lead and copper contamination. However, these same tenets reflect the difficulties in accomplishing such a task, where interfaces between multiple organizations, new policies, required new information, immediacy, costs and the power to accomplish this major task may be problematic. Although the following statement may sound harsh, political decisions drive the trade-offs between financial costs and public health, and occasionally reality ill affords the money to apply ethics. Are ongoing deaths and illnesses every year sufficient to change the way that all of the U.S. and international water systems operate?

\subsection{Public Health Implications}

A letter to the U.S. Environmental Protection Agency and the U.S Centers for Disease Control stated that "this paper affects the safety of the U.S. water supply. Basically, new research identifies a new pathway to explain E. coli outbreaks. Hundreds of thousands of yearly cracks in water mains permit E. coli ingress from soils during power outages, and when water mains are restored to service E. coli bacteria are pushed to end users in front of the chemicals that are added to water mains for decontamination. Consequent illnesses and deaths follow" . Additionally, lead and copper health hazards are increased by water hammers that damage water mains.

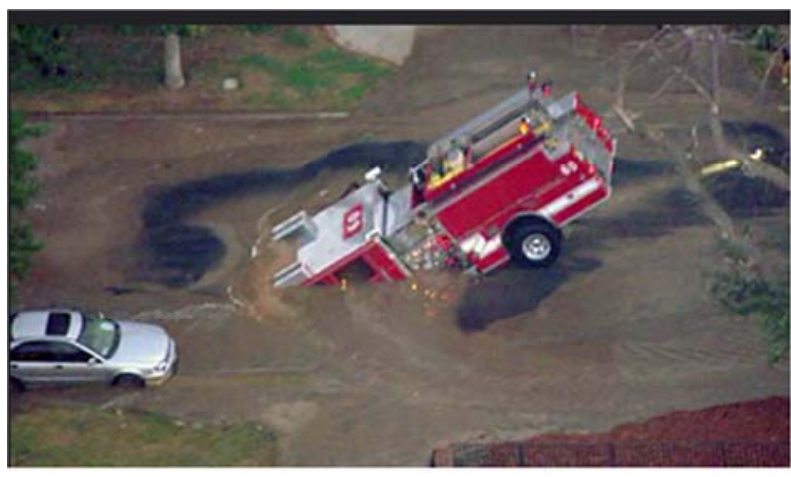

Figure 5. Los Angeles Water Main Break, September 8, 2009 (Reprinted by permission of Capitol Weekly).

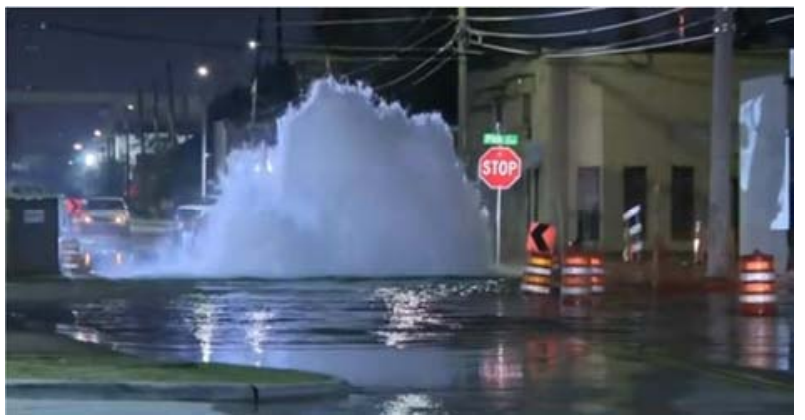

Figure 6. Houston Water Main Break, February 2, 2021 (Adapted from Click2Houston.com).

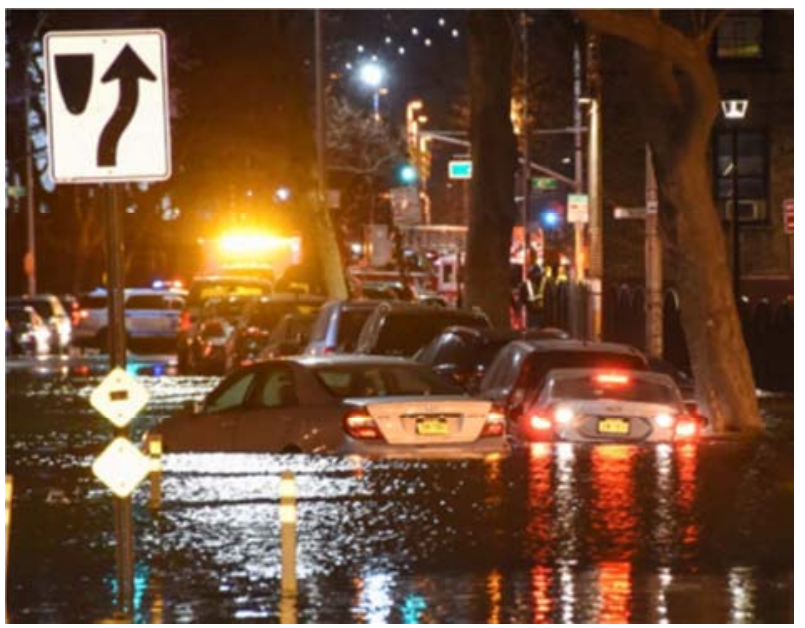

Figure 7. New York Water Main Break, January 28,2021 (Adapted from The New York Post).

\footnotetext{
${ }^{1}$ Neither the Centers for Disease Control nor the Environmental Protection Agency responded to inquiries about these public health concerns.
} 

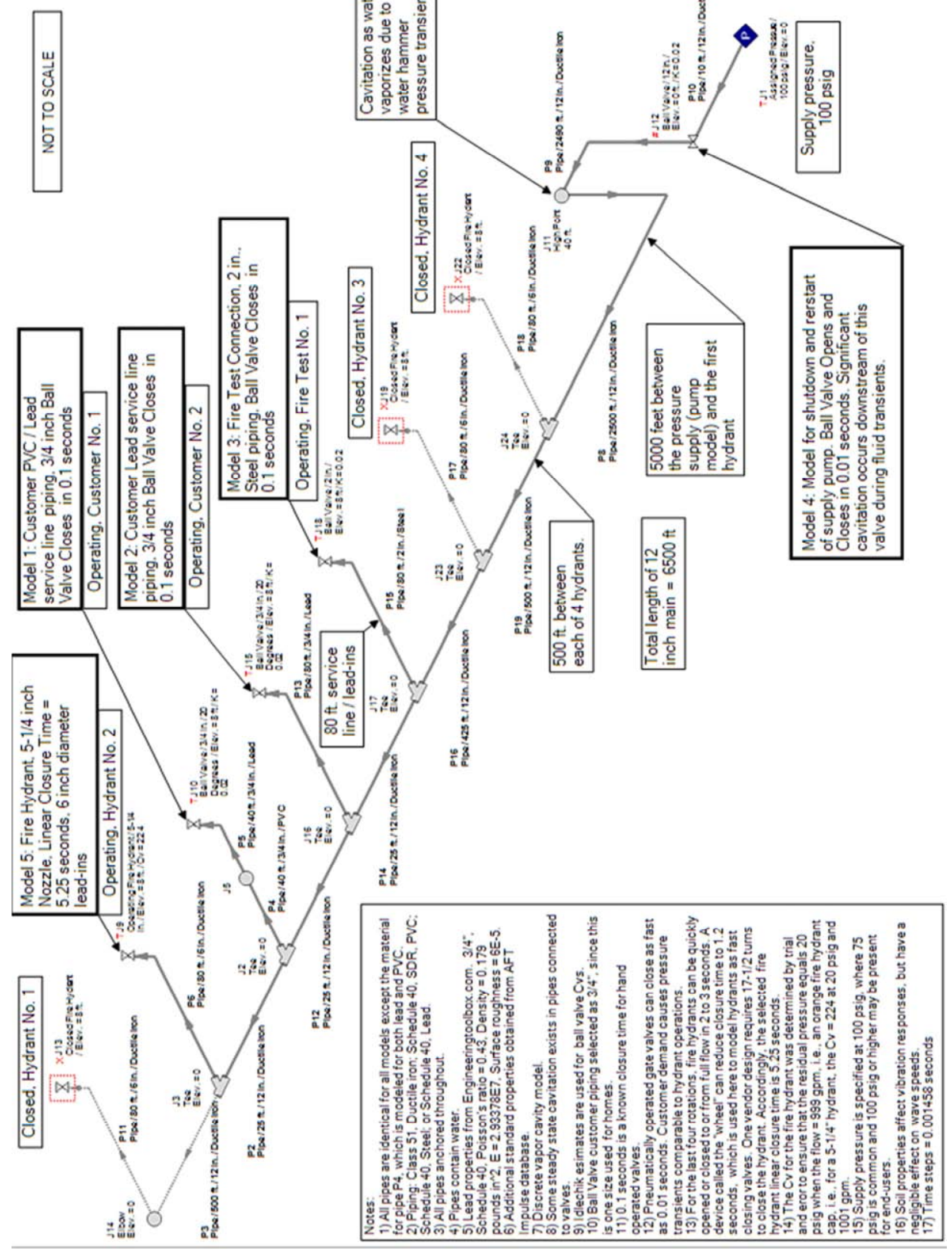

Figure 8. Water Hammer Models for Water Main Break Failure Analysis, Process and Instrumentation Diagram. 
Static Pressure vs. Time at the End of the 12 inch Ductile Iron Pipe

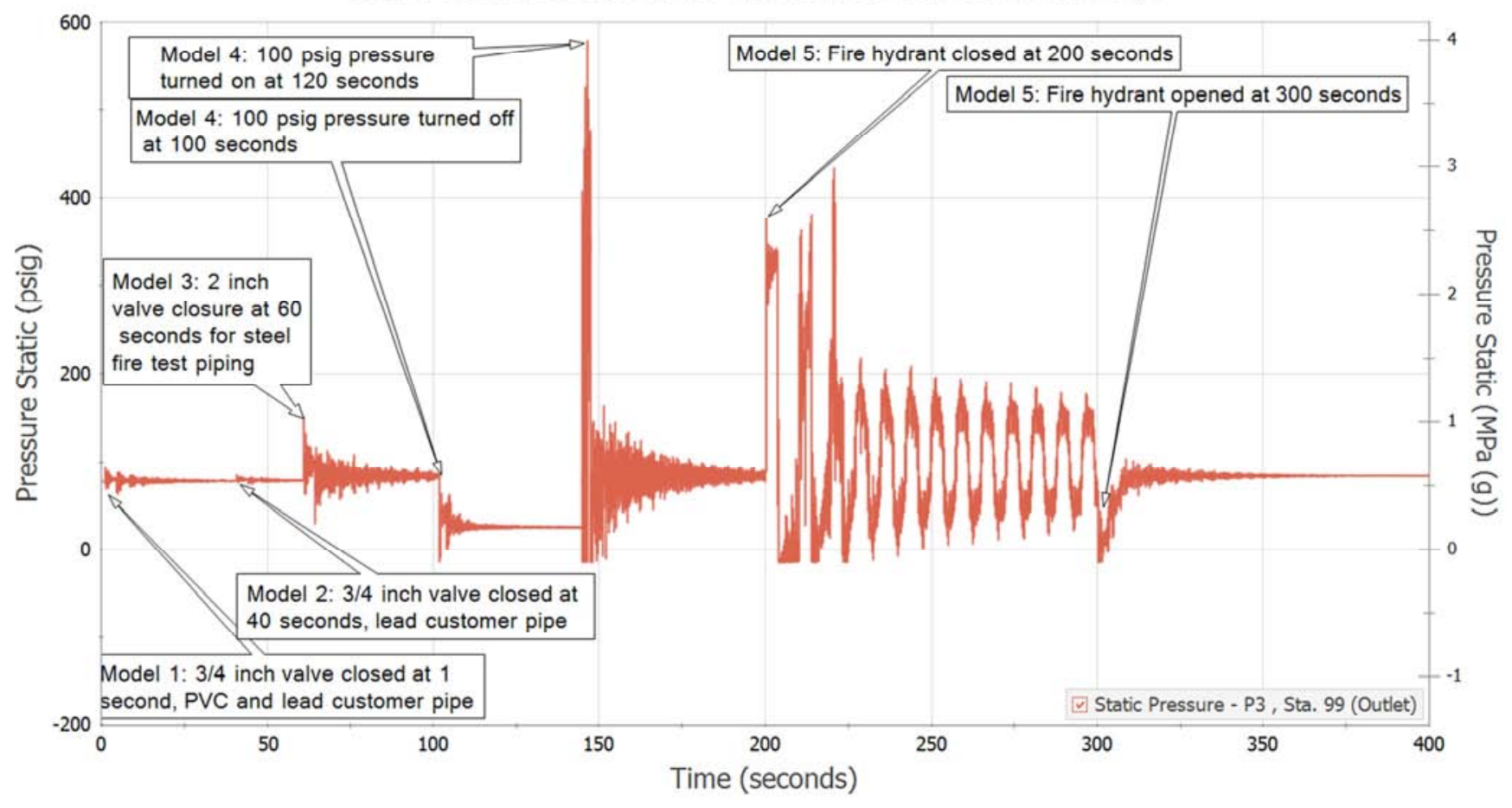

Figure 9. Transient Pressures at the End of the 12 Inch Main.

Static Pressure vs. Time for Comparison of Pressures at the Valves for the Lead Lead-in to the Lead / PVC Lead-In

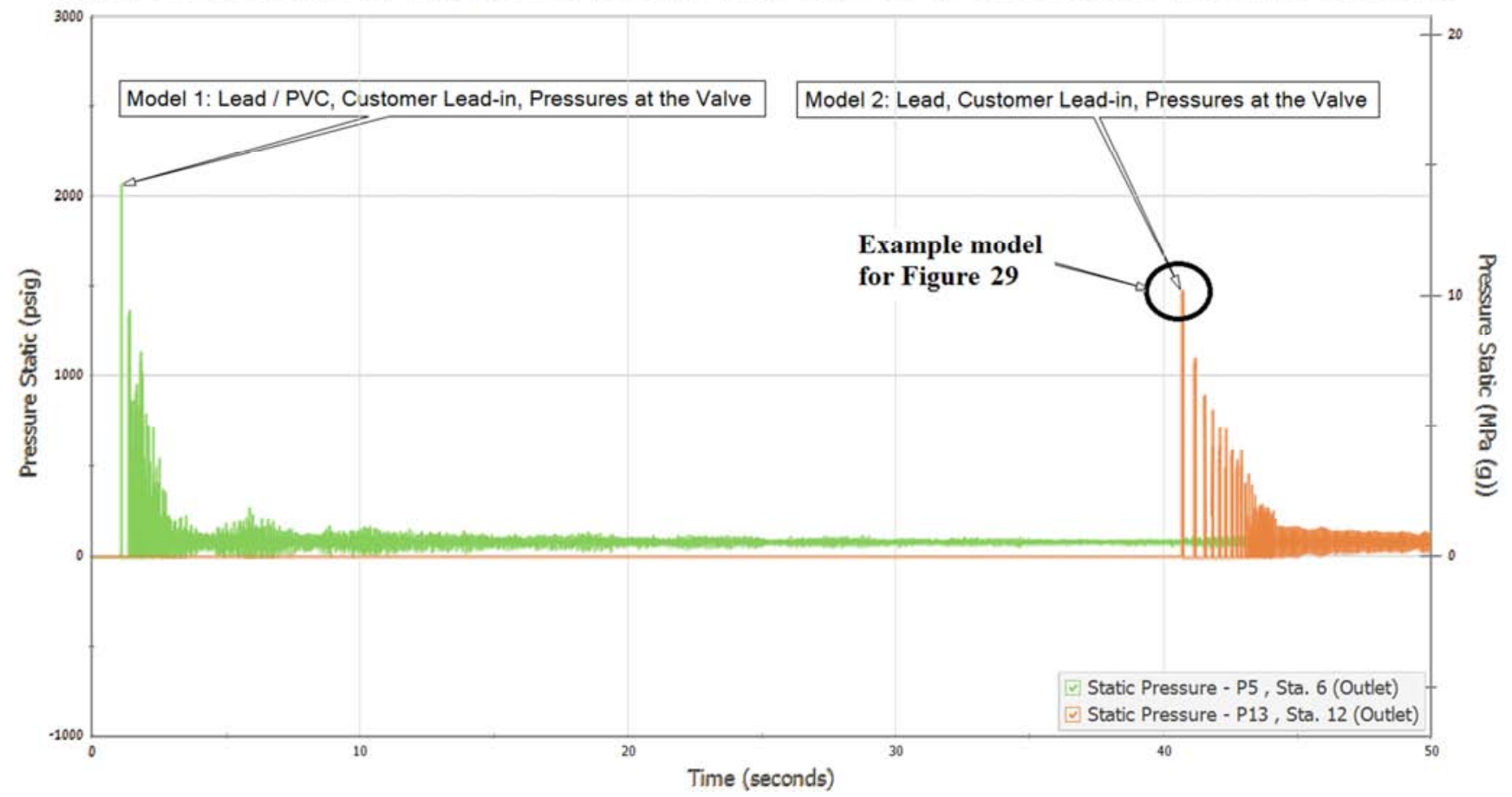

Figure 10. Comparison of Pressures for Lead vs. Lead / PVC Service Lines.

\section{Water Main Breaks}

\subsection{An Overview of Water Main Breaks}

Research continues and the following discussion considers the current understanding of water main breaks by presenting water main models and data that are new to the literature.
Specifically, a simplified water main system is presented to understand the some of the complex water hammer interrelationships between fire hydrants, fire system test valves, pumps and piping materials. Also, actual field corrosion data for a steel piping system is presented, where this data is part of a current failure analysis investigation.

Photos display a few of the many dramatic water main 
breaks that have occurred. Figure 5 shows the effects of a water main break that scoured away the soil under a road, and the road collapsed, and a fire engine fell into the gaping hole that was concealed by murky water flowing from the water hammer broken water main. Figures 6 and 7 show the effects of ruptured mains that were split by water hammers.

Each of these water main breaks, along with myriad other breaks, followed power outages. For example, in February of 2021 power outages and subsequent pump restarts directly resulted in major water main breaks in cities that included New York, Chicago, Philadelphia, Pittsburgh, Baltimore, Bloomington, Cincinnati, Saint Paul, Memphis, Berkley, Chattanooga, San Antonio, Dallas - Fort Worth, Austin, Houston, and many others.

System disinfections were effective to stop E. coli infections following these major water main breaks, where the Centers for Disease Control did not report major outbreaks following these February water main breaks. The times to system restart and the extent of system decontamination affect infection rates. In other words, power outages with less noticeable underground water main breaks are more likely to infect water supplies, where disinfection actions may not be as comprehensive and effective since breaks are not so obvious.

\subsection{A Water System Model}

To better understand water hammers in water systems, the simplified model under consideration is shown in Figure 8. This model includes a single main and seven lead-in pipes teed from a 12 inch diameter, ductile iron header. The lead-ins tie into four hydrants (Hydrant Nos. 1-4), a typical building fire test valve (Fire Test No. 1), and two other pipes that evaluate the effects of polyvinyl chloride (PVC) versus lead in service piping (Customer Nos. 1 and 2). Notes on Figure 8 provide dimensions and comments to describe model details. Many different models were investigated to provide a suitable representative model to investigate some of the intricacies of water hammer pressure surges in water supply systems.

Using this common Process and Instrumentation Diagram, five different models were constructed by opening and closing different valves in the models. AFT Impulse [22] was used to perform all models, where this computer code has been NQA-1 qualified [23].

To facilitate the presentation of data, one of the fire hydrants was assumed to be closed while a fire test valve and the two customer valves were open. These hydrants and valves were open at the start of the models (Time $=0$ ), and only the hydrant remains open at the end of the model. In this manner the approximate effects of each model are displayed on a single graph, and the graphs are then expanded to elucidate specific water hammer topics of concern.

This graph is shown for a location at the end of the main in Figure 9, where the piping is effectively a dead end since the hydrant is closed at this location. Note that the small diameter customer service line piping caused minimal pressure surges in the larger diameter main, as expected since transmitted waves from the smaller diameter pipes into larger diameter pipes are dwarfed by the reflected pressure waves at the interface between the small and large diameter pipes. Also note that the largest pressures throughout this model are located near the dead end where reflected pressure wave effects are largest.

\subsubsection{Model 1: Combined PVC and Lead Customer Piping}

Model 1 consists of a PVC piping lead-in connected to lead piping that is connected to the customer. Note that the maximum 2075 psig pressure (Model 1, Figure 10) is considerably higher than the 1476 psig pressure (Model 2, Figure 10) at the valve for a lead-in pipe, or service line, that is only constructed of lead.

This observation demonstrates an important principle of reflected waves at the interface of two different materials. There is a significant reflection of pressure waves at the interface between two materials in a pipeline when a water hammer wave reaches that interface. That is, a reflected wave occurs when a pressure wave is induced in the harder material, and this pressure wave reaches the softer material. That is, if a valve is suddenly closed and is attached to a hard material (lead), a shock wave goes down the pipe. If this hard pipe (lead) is connected to a softer pipe (PVC), reflected waves will occur where the softer (PVC) and harder (lead) material connect together. As a result these reflected pressure waves add together to increase the pressures in the lead service line, as the pressure waves bang back and forth in the lead service line.

In fact, this principle is used to control pressure surges in some cases. By inserting a rubber spool piece between the water hammer source and the rest of the piping system, most of the pressure surge is effectively blocked from the rest of the system through the processes of wave reflections at the material interface.

A second observation is that pressures are considerably higher in the piping connected to the valve, and this phenomenon is also due to wave reflections from the material interface. For the work considered here, earlier practices for replacing lead service lines was to replace only the city water supply piping and let the customer replace the lead pipes on their property. The fact was recognized that this practice contaminated customer drinking water. In fact the National Association of Corrosion Engineers lobbied congress to replace lead piping, and claimed that new construction damaged lead service lines. The fact is that attaching PVC piping, increased the lead service line stresses, and damaged the pipes to induce lead into customer drinking water.

In other words, what was considered to be a solution actually worsened the contamination problem. Current laws require that all lead piping should be replaced, and although this reflected wave problem will be inadvertently resolved, high piping pressures are expected to continue lead contamination. That is, water hammer pressures cause sufficient pressures to induce lead corrosion and water contamination, as evidenced by past customer contaminations. 
Static Pressure vs. Time in the Fire Test Piping

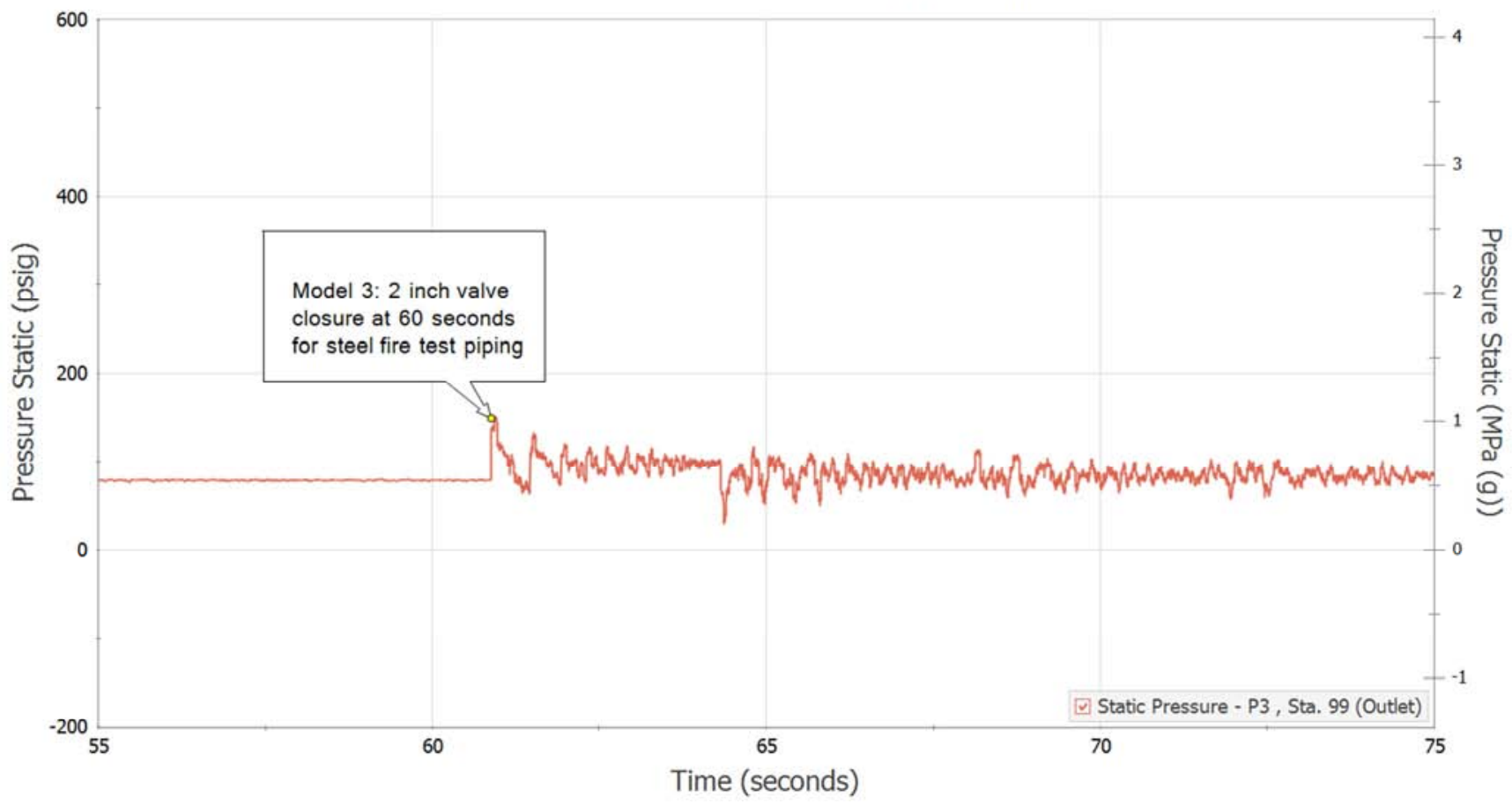

Figure 11. Inlet Pressures for Fire Test Piping.

Static Pressure vs. Time During a Power Outage

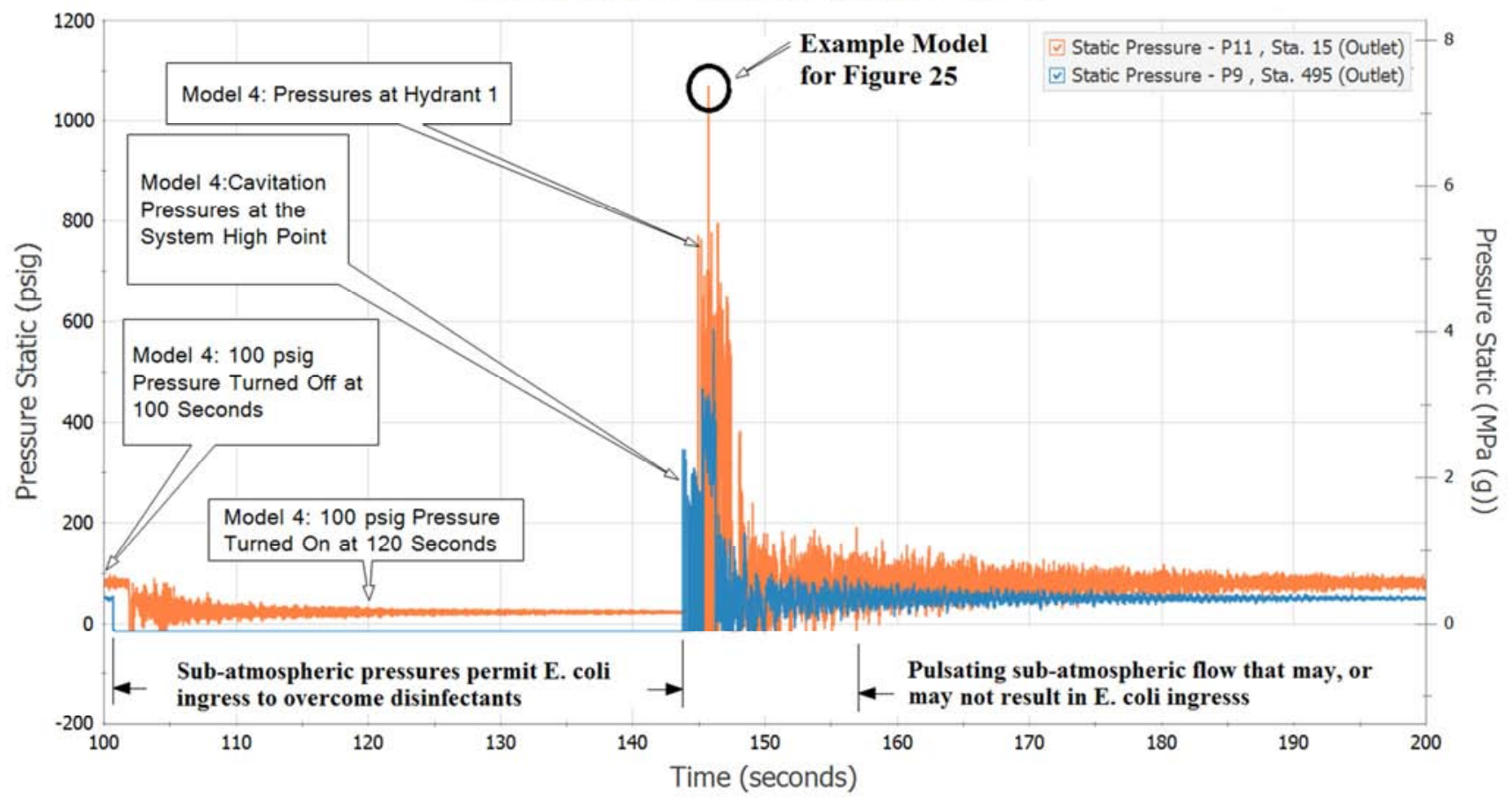

Figure 12. Maximum Pressures During a Power Loss. 


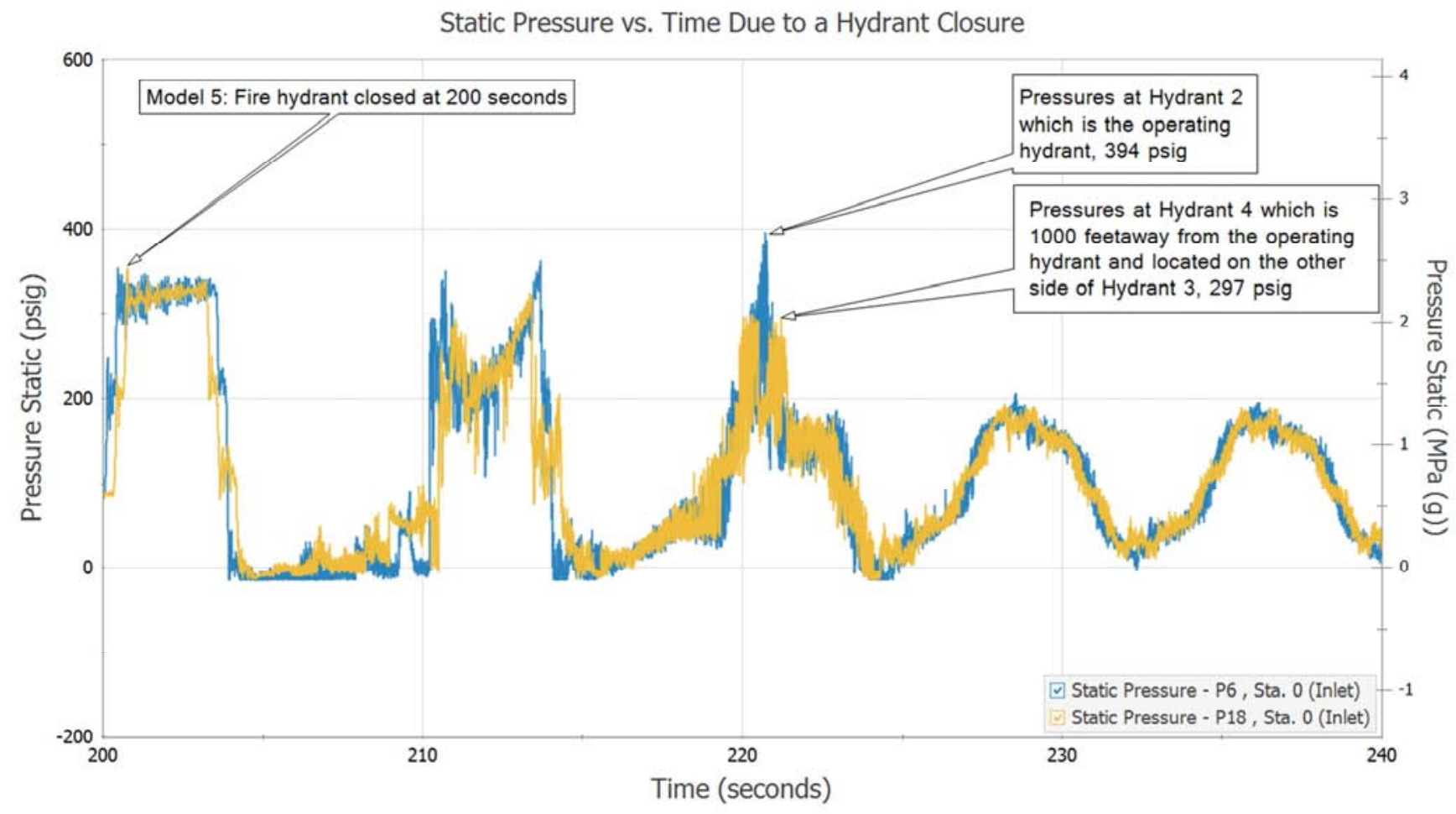

Figure 13. Pressures Due to a Hydrant Closure, Piping Inlets.

Static Pressure vs. Time Due to a Hydrant Closure

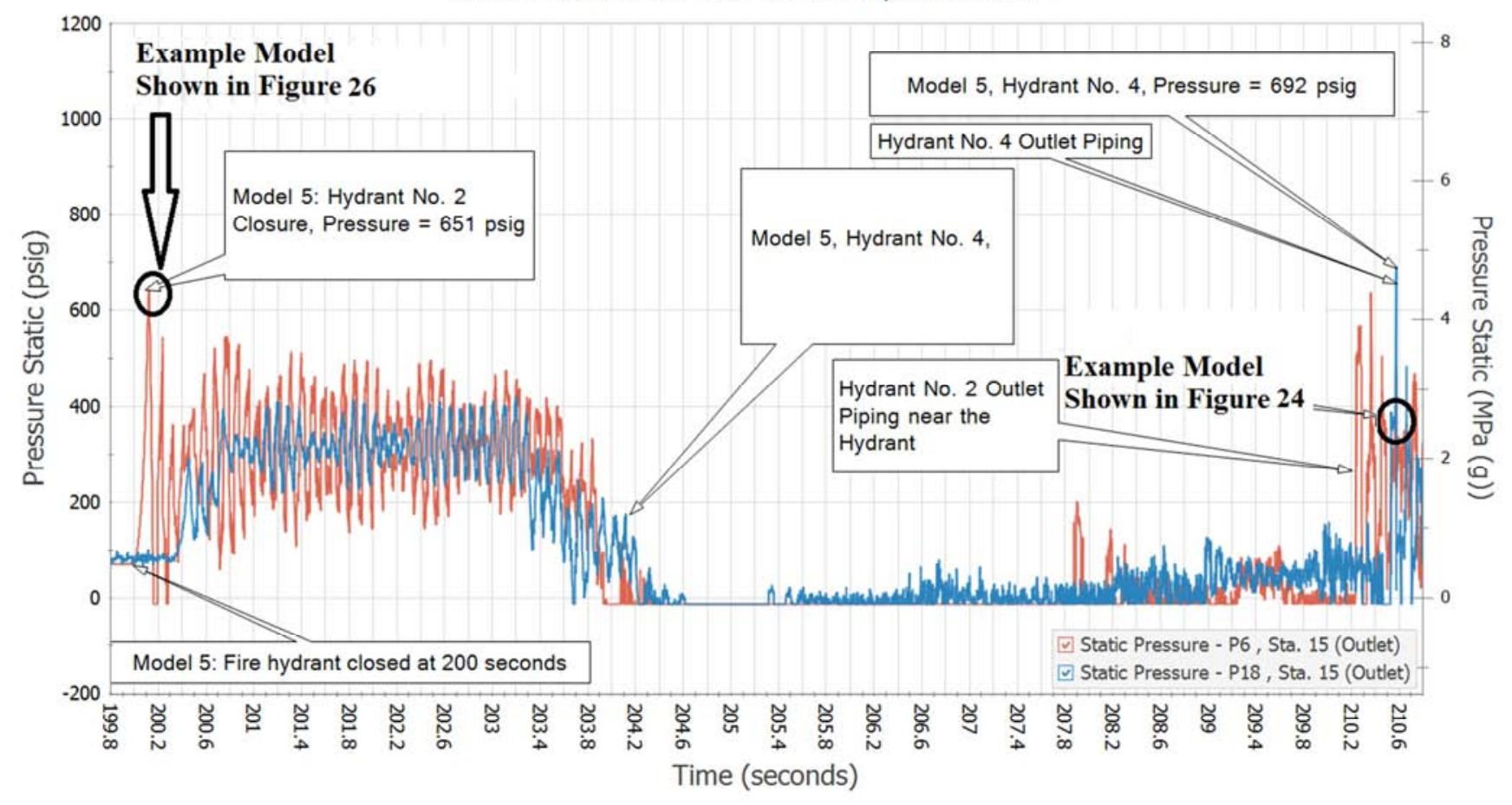

Figure 14. Pressures Due to a Hydrant Closure, Piping Outlets.

\subsubsection{Model 2: Lead Pipe to the Customer}

Model 2 consists of single lead piping lead-in / service line to a theoretical customer. As noted in Figure 9, minimal pressures (87 psig, Model 1, Figure 9) are induced in the 12 inch main by the closing of the valve on the lead service line, while the maximum pressure in the service line is $1476 \mathrm{psig}$
(Model 1, Figure 10). Basically, the opening and closing of valves in homes and other small water use customers has little effect on the larger water mains.

\subsubsection{Model 3: Fire System Testing}

Annual fire tests are required for industrial facilities and multi-story buildings. Since testing the entire fire system is 
impractical, tests are conducted near the entry point of the water supply to the building. A two inch ball valve is a common valve installed to test the supply, and water is dumped by pipes or hoses to drain from the building to perform fire system tests. These valves can be closed in about $1 / 10$ of a second as modeled here. The calculated 152 psig pressure (Model 3, Figure 11) is not a major contributor to fatigue damages, but may contribute to long-term piping fatigue damages.

\subsubsection{Model 4: Pump Shutdown and Restart}

There are many combinations of water supply pumps, design pressures, and piping designs, but only one design was selected here. A typical pressure of 100 psig was selected since 70 to $80 \mathrm{psig}$ is a preferred pressure to be supplied to households. Since there are many pump designs, a constant pressure was assumed to simplify this model, where features such as the piping dimensions and the moment of inertia of the pump and motor affect the system pressure responses to pump operations. That is, maximum pressures due to pump start up are shown (Figure 12), and actual pressures may be less. Once again, some of the highest pressures occur at the dead end of the piping at Hydrant No. 1.

Also note that cavitation pressures occur at the system high point. Although cavitation, or vapor collapse, pressures are not the largest pressures in this system, this type of hammer has caused major system damages in fire suppression systems, and should be evaluated carefully for system designs.

Table 1. Fire Hydrant Identification Colors and Ratings.

\begin{tabular}{lll}
\hline Color & Class & $\begin{array}{l}\text { Required Minimum Flow, gpm, @ 20 psig } \\
\text { residual pressure }\end{array}$ \\
\hline Blue & AA & $>1500$ \\
Green & A & $1000-1499$ \\
Orange & B & $500-1499$ \\
Red & C & $<500$ \\
\hline
\end{tabular}

\subsubsection{Model 5: Fire Hydrant Closure}

Figure 13 shows the inlet pressures at Hydrant No. 1 and Hydrant No. 4, which is the closing hydrant that generates the transient pressures. A close inspection of the pressure histories clearly shows that the placement of Hydrant 3 between these two hydrants affects the pressures at Hydrant 4 . However, the outlet pressures for Hydrant 1 and Hydrant 4 in Figure 14 also clearly shows that a closing hydrant at one location affects the pressure surges at other hydrants, where complex reflected waves in the piping system are extremely important to piping failures.

For example, the maximum equivalent pressures at the outlets of Hydrant 2 and Hydrant 4 are 1216 psig and 716.5 psig respectively. The pressures in the piping near the closing Hydrant 2 is expected to cause more damage than the pressures near Hydrant 4, but the pressures are certainly important to piping damages. The concept of Dynamic Load Factors is introduced in subsequent paragraphs, where dynamic load factors (DLFs) were used to estimate these pressures. A DLF is a multiplier that is used to capture the effects of suddenly applied pressures. For example, if a pressure wave travels along the length of a pipe that pressure creates pipe stresses. If those stresses are slowly applied inside the pipe, a static hoop stress results. For a $D L F=4$, the dynamic stress equals 4 times the static stress. His dynamic stress is the actual stress that is exerted on the pipe due to a high speed pressure wave caused by water hammer.

There are different hydrant manufacturers, different hydrants perform differently with respect to transient pressures, and hydrant performance data is not readily available. For this work a video of actual hydrant performance was used to establish the flow coefficient, or $C v$, with respect to the opening percentage of the hydrant, where the $\mathrm{Cv}$ is related to the frictional resistance across avalve.. To do so, a video of a flow test was carefully studied, where $171 / 2$ turns were required to turn the nut on the top of the hydrant until it stopped. However, the pressure gauge attached to the hydrant showed that the maximum pressure was obtained during the first 4 rotations of the nut. Pressures were observed during rotations - and using the relationship that the pressure is proportional to the square of the flow rate - a ratio of pressures to flows was obtained, but a $C v$ was still required. A minimum $C v$ was obtained by trial and error for this system (Figure 14) by understanding that the delivery pressure must be at least 20 psig for a 1000 gpm delivered flow (See Table 1). The fact is that in-service flow rates for hydrants are likely higher at this pressure, but this flow provides a design pressure for this model, i.e., higher flows and higher $C v s$ will yield higher system pressures during transients. The hydrant $C v$ was varied using this model until the pressure and flow met this design requirement (Figure 15). Other requirements could have been specified as shown in Table 1.

Additionally, the opening of a valve in the modeled system to a depressurized section of piping, would cause pressures indicated in Figure 12. This situation can occur when traditional gate valves are replaced with butterfly valves to save costs, as witnessed on occasion by this author for actual systems.

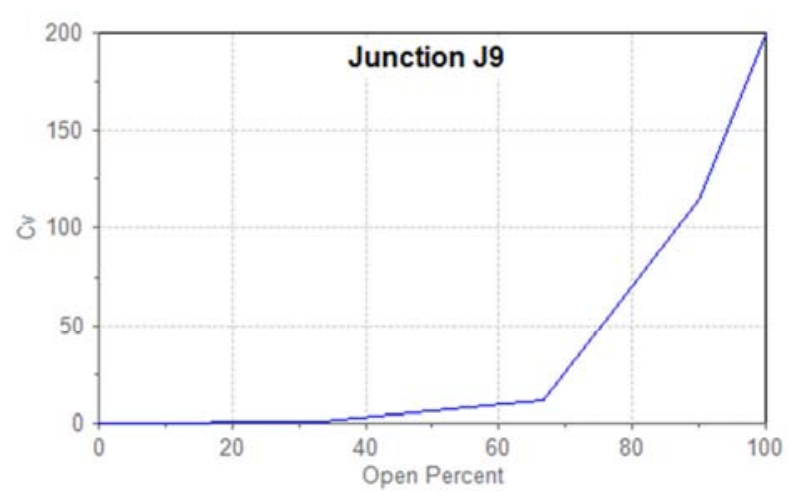

Figure 15. Lower Limit of Cvs for Fire Hydrants.

\subsection{Water Main Failure Causes}

\subsubsection{Previous Research}

Previous publications by this author were sufficient to prove that water hammer breaks water mains, but this study provides important new insights into the failure causes of 
water mains. Even so, additional research beyond this work is recommended to better understand water main breaks. Approximately 70 percent of water main breaks are cracks alone, and approximately 30 percent are related to corrosion. Cracks are directly caused by high stresses due to water hammer, and corrosion is more complicated. Cracks provide an initiation point to accelerate corrosion, and high stresses also affect corrosion rates, where this last statement is new to the literature. All of these failure mechanisms are related to fluctuating stresses due to water hammer.

To paraphrase an earlier book (Leishear [7]), pressure waves induce fluctuating strain waves, which travel along the bore of a pipe near the sonic velocity of the fluid in the pipe. Using Newton's Law, a lot of calculus, and the equations of motion for a thin walled tube, the maximum DLF due to this process was experimentally to be shown to be less than 4 .

The experimental basis for DLFs for hoop stresses was found by measuring water hammer pressures, measuring strains in the piping, and converting those strains to stresses using the modulus of elasticity for 3 inch nominal pipe size, Schedule 40 stainless steel pipe. The basic system layout for the 710 feet long piping system is shown in Figure 16. Measured pressures are shown in Figure 17, and Measured Strains are shown in Figure 18. The strain waves were in reasonable agreement with the closed form solution, and the maximum DLF was less than 4 for all measurements, where damping decreased the maximum DLFs, where the maximum DLF is multiplied by the calculated water hammer stress to determine a maximum failure stress.

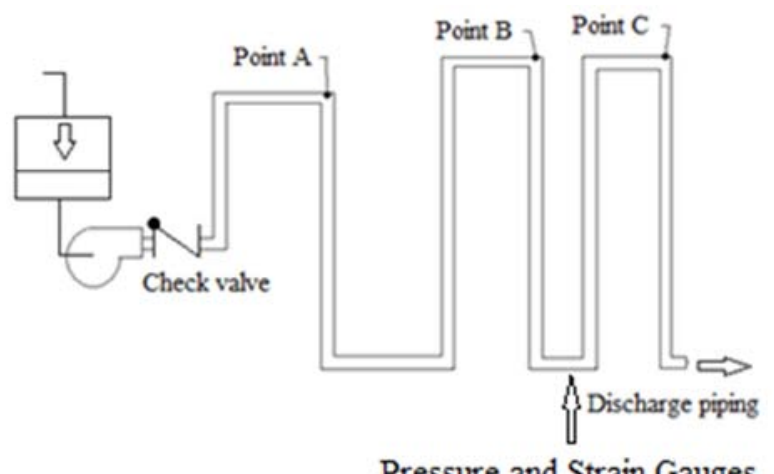

Figure 16. System Diagram for Water Hammer Tests.

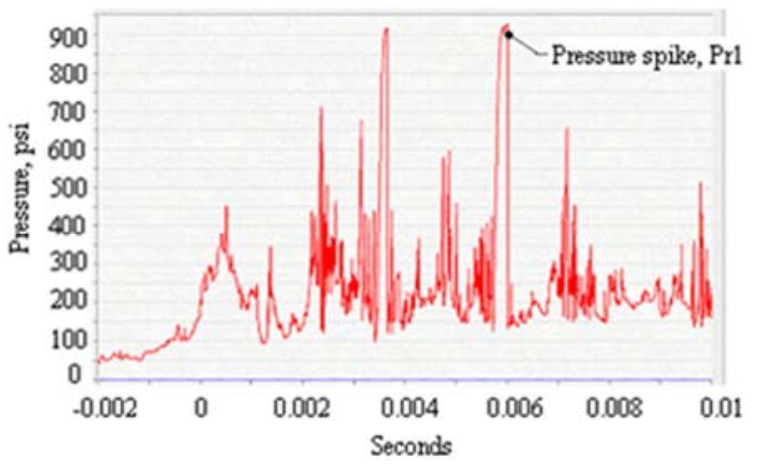

Figure 17. Pressure Measurement in a 21 psig System.

\subsubsection{New Findings}

There have been two open questions for a long time with respect to this ongoing research. The first question still needs to be addressed, and can be stated as "What are the effects of pipe sizes on DLFs". This author's opinion is that there is little effect, but proof is required and research to address this issue is planned. The second question is partially answered here, and can be stated as "Why do the strain wave magnitudes fluctuate along the pipe, as observed in Figure 18?"

To begin to answer this question, note that pipes have multiple frequencies along their length, and that impact loads excite the first mode frequency of a pipe. Accordingly, any water hammer shock wave is expected to induce a fixed vibration in a pipe wall similar to the first mode vibrations along a pipe (Figure 20). Also, Beltman, et al. [26] performed research on explosive pressure waves in gas filled aluminum tubes. Permanent plastic deformations formed in the walls of the tubes, as shown in Figure 21.
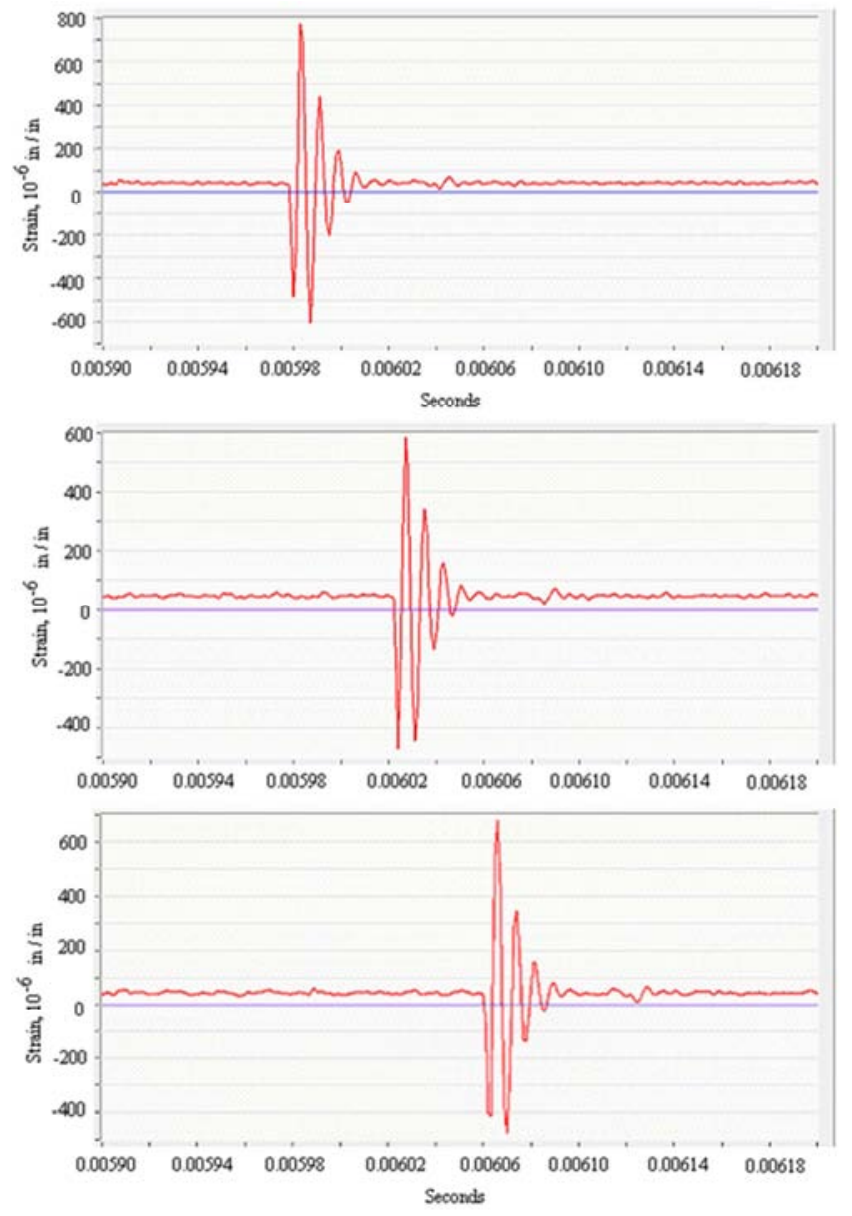

Figure 18. Strain Measurements (Prl=piezoelctric pressure transducer) Depicting Pressure Wave Effects Due to a Water Hammer (Leishear [7]).

A current research project found this same repetitive pattern in steel piping subject to 1500 psig pressure shock waves. Later publications are planned to address this complex phenomenon, but the novelty of this finding merited publication here. Stress corrosion cracking has been documented for numerous materials, but this newly identified 
process of fatigue corrosion is unique to the literature. Figures 22 and 23 show bands of corrosion that mimic the fluctuating stress patterns that are observed during the transmission of pressure waves in piping. These observations also fit the data collected in Figure 18.

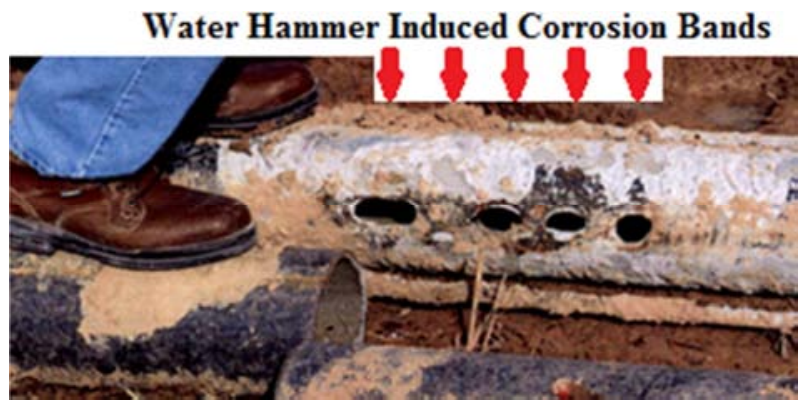

Figure 19. Evidence of Pressure Bands and Fatigue Induced Corrosion (Adapted from Leishear [3]).

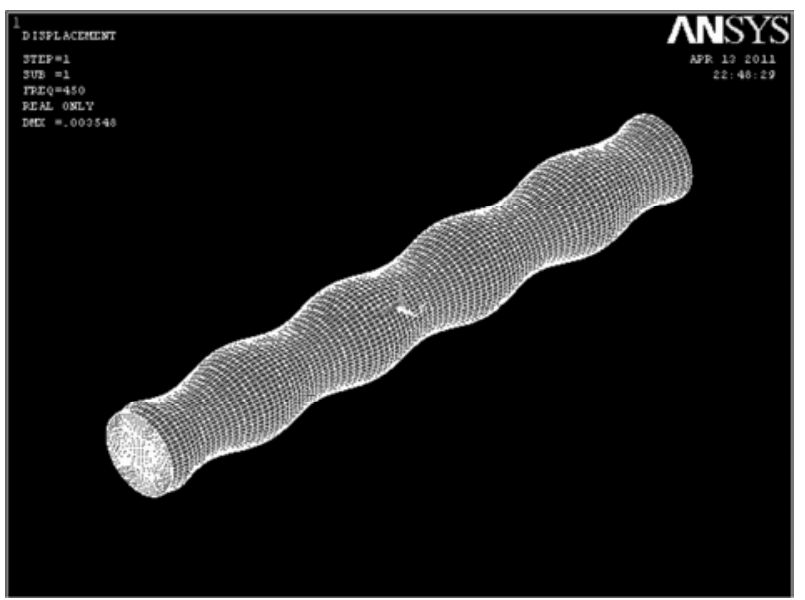

Figure 20. First Mode Vibration Frequencies in a Pipe (Adapted from Dweib [25])

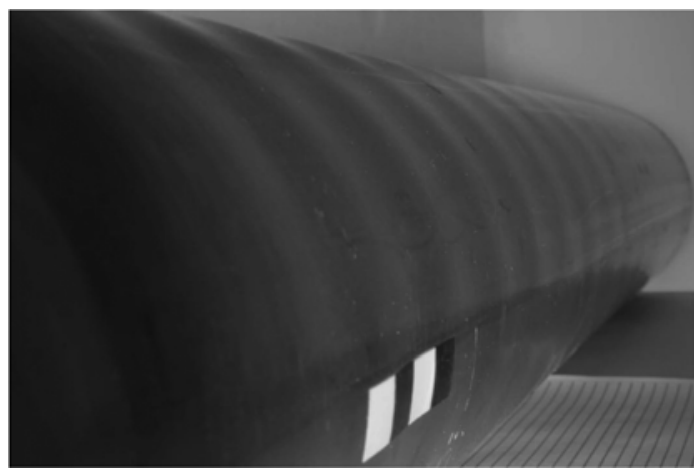

Figure 21. Experimental Demonstration of First Mode Frequencies (Beltman [26]).

Another previous project showed banding of corrosion as well. In this case, the maximum stresses occurred at the mid-height of the piping, since there was 8 feet of soil above the 8 inch ductile iron piping (Figure 20). Pipe ovalization added additional stresses to the water hammer stresses, where the additional stresses due to soil pressure may be approximated (NTSB [28]).

There is still research to be done to understand this corrosion mechanism. In this author's opinion, the localized high stresses crack the mill scale on the steel to cause local corrosion between the anodic mill scale and the cathodic steel surface. That is, high cyclic stresses result in corrosion. This concept of fatigue corrosion, rather than corrosion fatigue, is new to the literature.

The evidence is clear. Stresses, strains, and corrosion in pipe walls fluctuate due to water hammer waves.

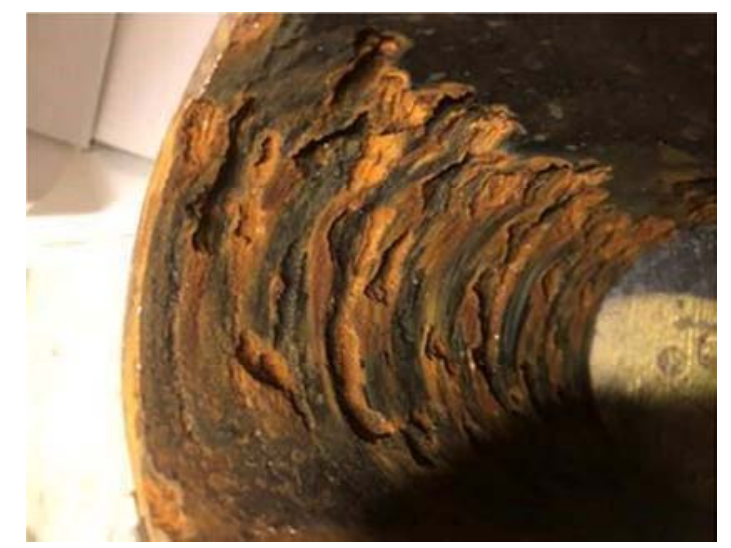

Figure 22. Bands of Fatigue Due to Water Hammer Pressure Waves.

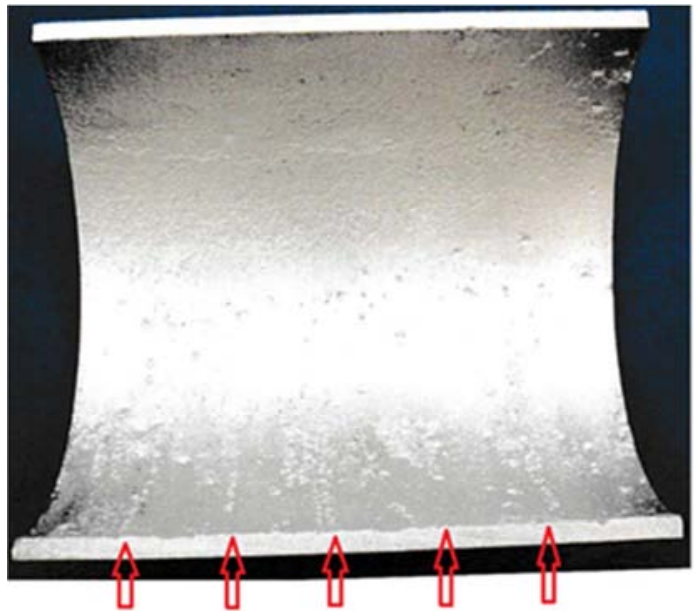

Figure 23. Incipient Bands of Fatigue Due to Water Hammer Pressure Waves - Surface Cleaned For Corrosion Evaluation.

\subsection{Dynamic Load Factors and Maximum Pressures}

\subsubsection{DLFs for Hydrant Closures}

The dynamic load factor varies depending on the pressure rise time, the pipe wall frequency, and the pressure magnitude. A finite element calculation is needed to concisely calculate DLFs, but approximations are provided here using single DLF models, noting that there are myriad pressures with associated DLFs available to cause fatigue failures of water mains for the models considered here. Figure 24 uses a selected pressure surge, and assumes that the response of the pipe wall can be represented by single degree of freedom equations. When using these equations, the complicated wave forms shown in Figure 18 are neglected, and only the maximum stress value is considered (Leishear [7]). Then the maximum DLF=4 when damping is 
neglected. The DLF may actually be smaller due to the fact that the soil acts as a second spring in this complex two-degree-of freedom system. This approximation merits a later finite element evaluation.

After Leishear [7], the ramp response for a thin wall tube approximation is approximated as follows.

$$
\begin{gathered}
t_{1}=2.5326-2.5305=0.0021 \text { seconds } \\
\omega_{\text {pipe }}=\sqrt{g \cdot \frac{\frac{2 \cdot k}{r \cdot T}+\frac{E}{\rho_{\text {pipe }}^{2} \cdot \frac{r \cdot \rho_{\text {water }}}{4 \cdot T}}}{\rho^{2}}}=7622 \mathrm{~Hz} \\
\omega_{\text {soil }}=2 \cdot \pi \cdot 4 \operatorname{seconds}=25.13 \mathrm{~Hz} \\
D L F<2 \cdot\left(1+\frac{1}{\omega \cdot t_{1}} \cdot \sqrt{2 \cdot\left(1-\cos \left(\omega \cdot t_{1}\right)\right)}\right)=4
\end{gathered}
$$

For this underground piping model, the maximum DLF exists between 4 and 2.25, where a larger DLF occurs when the frequency for the soil is included in Equation 4. This estimate provides a bounding estimate using the DLF $<4$, since the fundamental physics of the problem does not permit a clearly justifiable choice between the use of the pipe frequency or the soil frequency. For aboveground piping, and using this same example model the DLF $<2.25$. That is, this simplified approach provides more go-no go conditions to determine if further modeling is recommended.

$$
\begin{gathered}
\sigma_{\text {static }}=\frac{P \cdot r}{T}=7346 \mathrm{psi} \\
\sigma_{\text {dynamic }}=D L F \cdot \sigma_{\text {static }}=29363 \mathrm{psi}
\end{gathered}
$$

where $t_{l}=$ the rise time $=0.0021$ seconds; $\omega=$ the hoop stress frequency of the pipe $=7622 \mathrm{~Hz}$ (Earlier work showed that this frequency approximation underestimates the frequency for a thick wall pipe, but this error does not significantly influence the maximum DLF for this example); $k=$ the bulk modulus of water $=140,000 \mathrm{psi} ; \quad r=$ the pipe radius $=3.45$ inches; $T=$ the ductile iron pipe wall thickness $=0.25$ inches; $g=$ the gravitational constant $=32.174$ feet $/$ second $^{2}$; $v=$ Poisson's ratio $=0.211 ; \rho_{\text {pipe }}=$ pipe density $=0.26$ pounds per inch ${ }^{3} ; \rho_{\text {water }}=$ water density $=0.03611$ inch $^{3} ; E=$ modulus of elasticity $=13,400,000 \mathrm{psi} ; \sigma_{\text {static }}=$ the thin wall approximation for a hoop stress based on the measured pressure; and $\sigma_{\text {dynamic }}=$ the dynamic stress which is the estimated stress to cause a fatigue failure in the pipe. Since the soil frequency is much lower than the pipe wall frequency, the soil frequency predicts a bounding maximum stress response, and the soil frequency was used for this single degree of freedom approximation to a two degree of freedom system. The soil frequency was obtained by noting that the measured vibration response to underground explosions in some soils is approximately 4 seconds, which yields a circular frequency of $25.13 \mathrm{~Hz}$ (Templeton, et al. [27]). The frequency of the soil is the same whether it is impacted by an explosion or a pipe wall expansion.

The stress calculated from Equation 6 will be used for a simplified analysis of fatigue due to water hammer pressure waves. For comparison to earlier research, consider the estimated go-no go conditions, or acceptance criteria, for water hammer induced stresses, such that

$$
\begin{gathered}
\Delta P=\rho_{\text {water }} \cdot a \cdot V+100=1087 \mathrm{psi} \\
\sigma_{\text {static }}=\frac{P \cdot r}{T}=20015 \mathrm{psi} \\
\sigma_{\text {dynamic }}=D L F \cdot \sigma_{\text {static }}<4 \cdot \sigma_{\text {static }}=80061 \mathrm{psi}
\end{gathered}
$$

where $a=$ the wave speed in the ductile iron pipe $=3770$ feet per second; and $\mathrm{V}=19.44$ feet per second (1919 gpm) the velocity of the initial velocity of the water flowing through the hydrant before the hydrant is closed.

Equations 1-6 were used to evaluate the initial pressures due to hydrant closure (Figure 26). The results are that the $\mathrm{DLF}=3.24$, the maximum stress $=652 \mathrm{psig}$, and the maximum hoop stress equals

$$
\sigma_{\text {dynamic }}=D L F \cdot \sigma_{\text {static }}=39827 p s i
$$

Note that the simplified calculation of the pipe stress is significantly higher than the stress calculation using the AFT model results 80061 psi $>39827$ psi (Equations 5 and 8), since the predicted pressure was substantially higher, such that, 2015 psi $>883$ psi. Also, the DLFs were smaller such that the range of the solution lies between DLF $<3.24$ and $\mathrm{DLF}<2$ (for aboveground piping for this same example model, the DLF < 2.00). The DLF=4 go - no go criteria successfully predicted that further analysis was warranted to obtain a reasonable estimate of the maximum pipe wall stress, but was significantly over conservative. Accordingly, there will be cases when this $\mathrm{DLF}=4$ go - no go criteria will predict a problem when the stresses will not be expected to cause fatigue damages. Models and full scale tests are always preferred to ensure a clear understanding of processes.

Again, a finite element analysis of stresses due to water hammer will provide greater precision and understanding for pipe stress estimates. On the other hand, if water hammers are controlled in municipal water supplies, an increased understanding is not so essential. The fact is that water hammer is destroying all of our water supply systems, and this destruction can be stopped. More research improves understanding but does not fix the ongoing water main break disaster.

\subsubsection{DLFs for Power Outages}

The maximum predicted pressures are summarized for one pressure surge in Model 4, Power Outage Model (Figure 25).

$$
\sigma_{\text {dynamic }}=D L F \cdot \sigma_{\text {static }}=79575 \text { psi }
$$

Note that the maximum stress of 79575 psi may, or may not, exceed actual stresses during power outages, since the startup time of pumps will cause a longer time to pressurize the system than the 0.1 second startup time used here, and the selected example model is the highest pressure near the end of the piping system. Even so, this author has observed calculated high pressures at isolated points throughout 
systems, where system pressures were doubled due to wave reflections.

For underground piping the maximum stress occurs in the range of $\mathrm{DLF}<4$ to DLF $<2.33$ For aboveground piping for this same example model, the DLF $<2.33$.

Calculations were performed in accordance with Equations 1-6. As mentioned, a conservative high pressure was calculated for this work since there are many combinations of pumps and pipe systems for power outages.

\subsection{Water Main Fatigue Failure Predictions}

\subsubsection{New Developments in Fatigue Theory}

The importance of the new finding with respect to multiple failure locations is profound with respect to water main breaks and fatigue failures. Fatigue curves are commonly used in failure analysis, where a fatigue test specimen is cyclically loaded, and the specimen usually cracks at the point of highest stress. For a fatigue test, there is only a single point of maximum stress failure. Considering Figures 22 and 23, a pipe subjected to cyclic fatigue from pressure waves will have many high stress locations. Specifically considering Figure 23 for a 6 inch nominal pipe size Schedule 40, ductile iron pipe, the distance between corrosion bands equals the period of vibration for the pipe wall, which in turns equals the distance between high stresses due to water hammer. The striking conclusion is that for a mile of pipe, there are 5280 feet $\cdot 12$ bands per foot $=63360$ potential failure locations.

In other words, for one mile of 6 inch steel water mains, there are 63360 locations that are each equivalent to a fatigue test failure. This new insight can be applied to piping fatigue failures as well as corrosion. Since each of these failures is an independent event, and fatigue is a statistically random process, the number of cycles to failure is additive when predicting the probability of fatigue failures. If there is one failure in 100,000 cycles, then there are two failures in 200,000 cycles for different locations, and so on. This information can be used to better understand the immense scope of water main breaks.

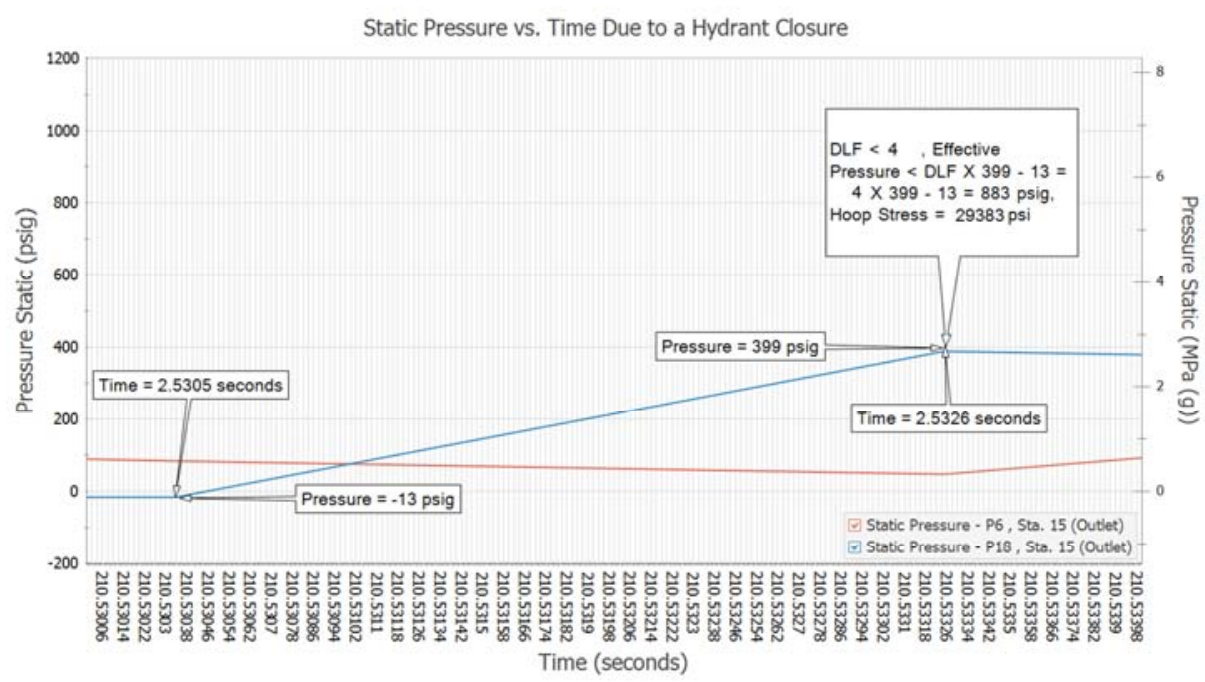

Figure 24. DLF Considerations for One of the Many Pressure Surges Due to a Hydrant Closure, As Shown in Figure 14.

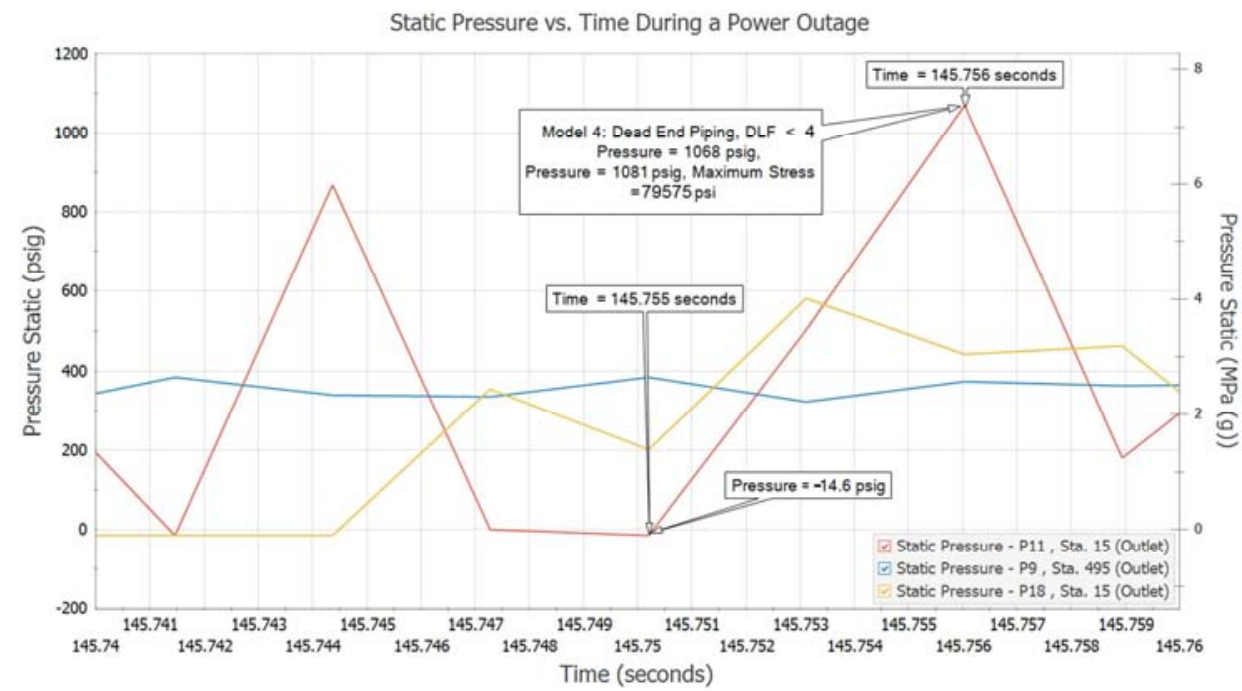

Figure 25. DLF Considerations for One of the Many Pressure Surges Due to a Power Outage, As Shown in Figure 12. 


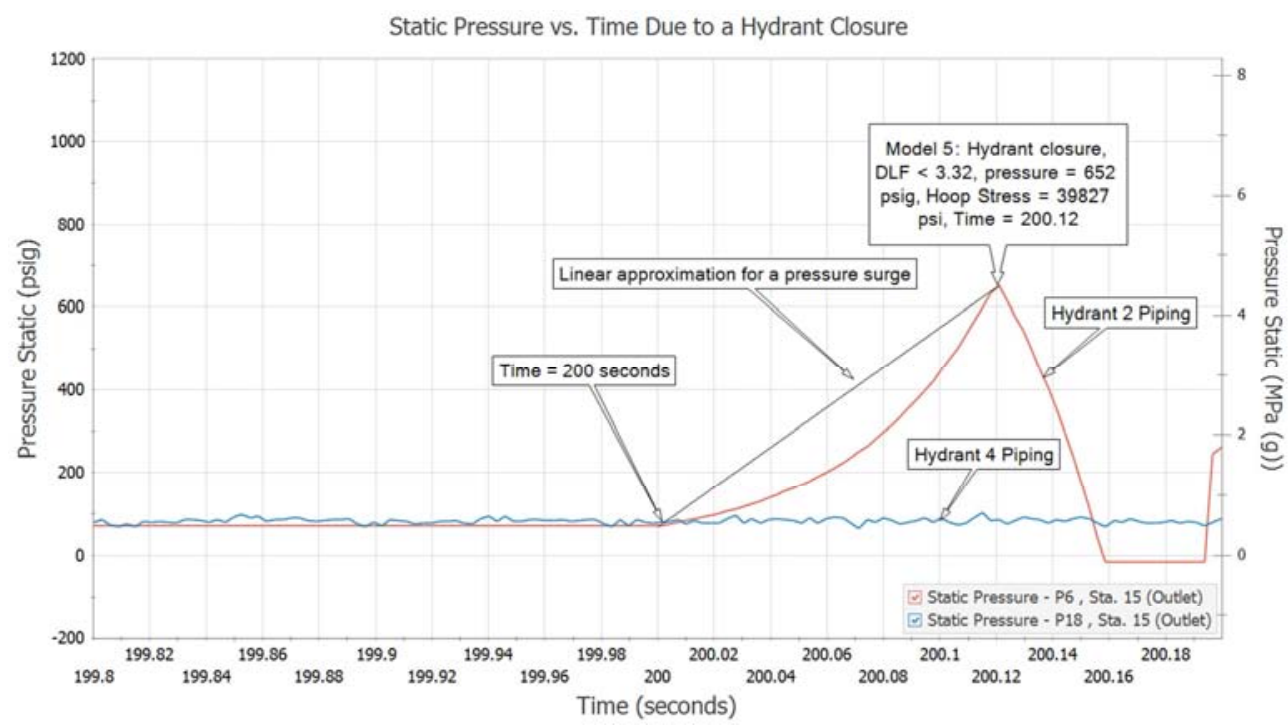

Figure 26. DLF Considerations for One of the Many Pressure Surges Due to a Hydrant Closure, As Shown in Figure 14.

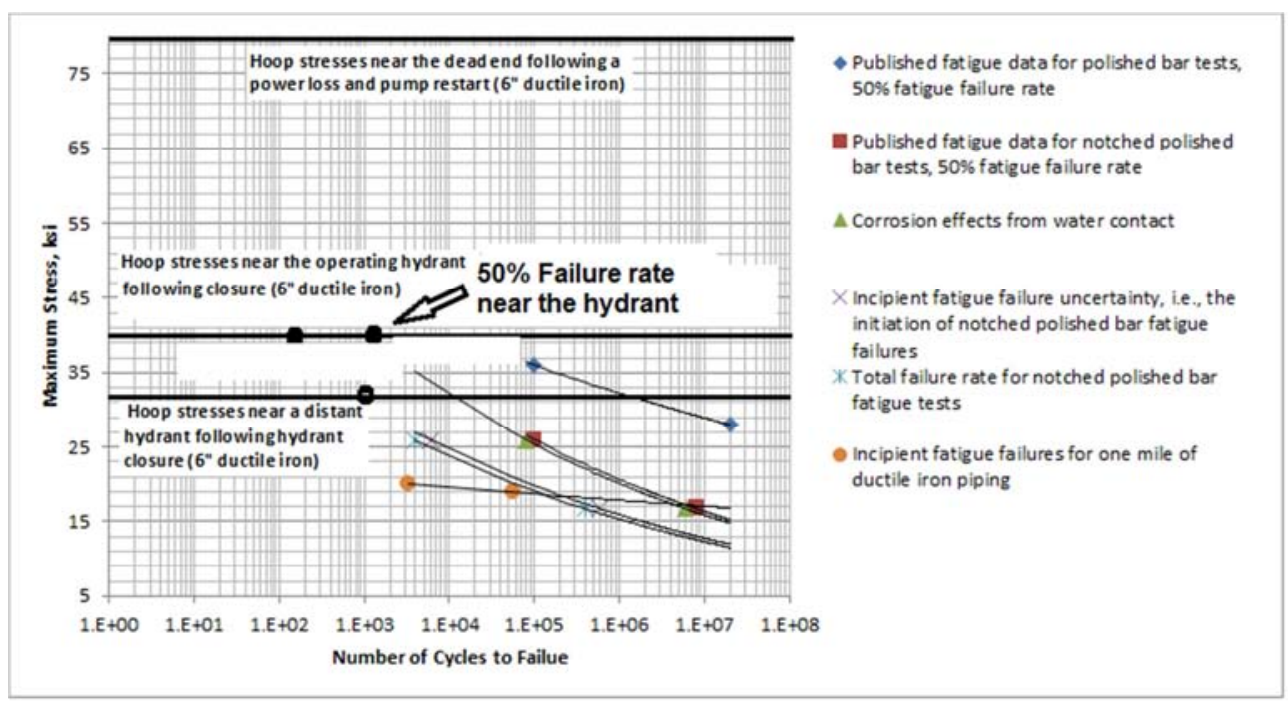

Figure 27. Ductile Iron Piping Fatigue Evaluation.

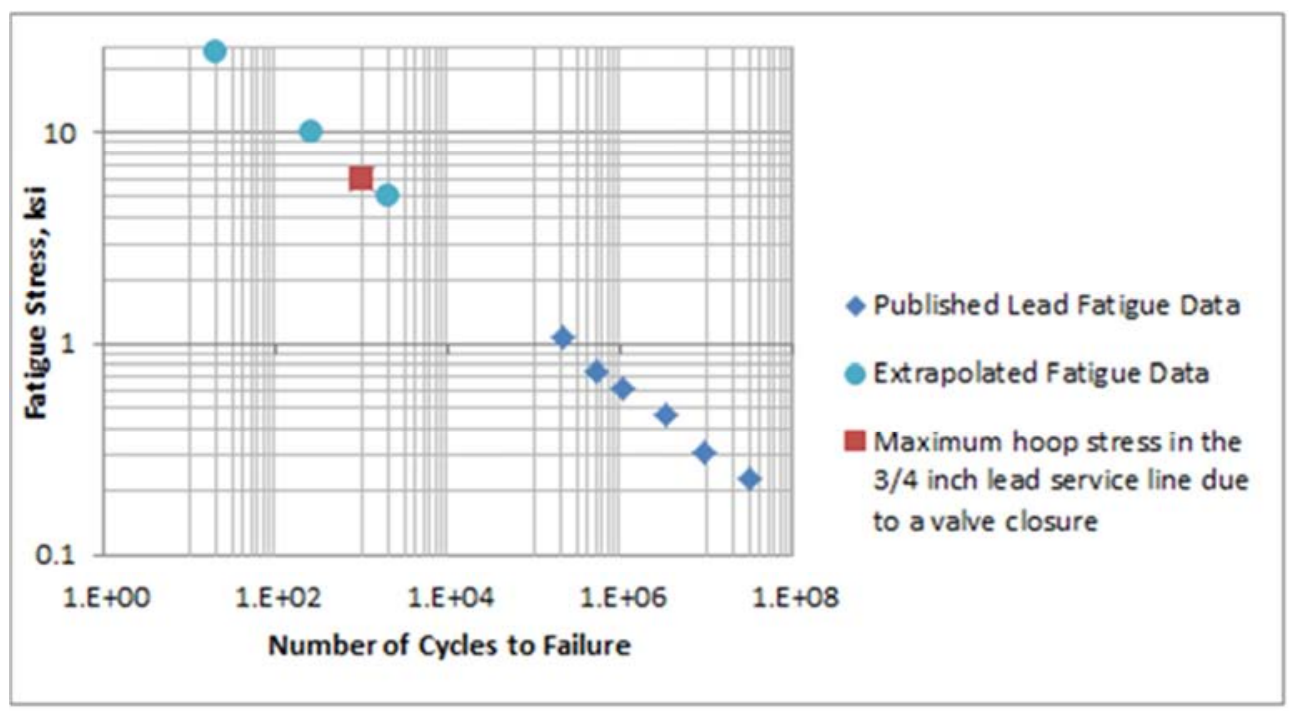

Figure 28. Lead Piping Fatigue Evaluation. 


\subsubsection{Ductile Iron Piping Fatigue Failure Calculations}

Since there is scant fatigue data available for water main failures, engineering judgement was used to investigate fatigue failures, and an appropriate fatigue curve was developed to understand water main fatigue failures, as shown in Figure 27. To construct the fatigue curve of Figure 26, the following steps were performed.

1. Published data for polished bar and notched polished bar fatigue tests were plotted.

2. Data is unavailable to account for nicks and scratches in the piping, and is unavailable to account for the effects of grit blasting for coating adherence when blasting was performed. Accordingly, notch bar tests are assumed to approximate scratch and surface finish effects.

3. The effect of corrosion on fatigue failures of ductile iron pipes is unavailable, but such effects are considered for a ductile iron material that is less affected by corrosion. Accordingly, that data was used to provide limited insights into the effects of corrosion on fatigue (Yakushi, et al. [29]).

4. Published fatigue curves provide data for the mean time to failure (Maruta, et al. [30]), but half of the failures occur by that time. Accordingly, a safety factor was used to establish an uncertainty that predicts the number of cycles to the first, or incipient, fatigue crack. Fatigue data typically falls within a range of plus or minus an order of magnitude, which was applied to the fatigue curve.

5. The number of failures per mile was determined, using the 63360 failures per mile for 6 inch ductile iron pipe for steel. Since ductile iron has a lower frequency than steel, the number of cycles was reduced by $5 \%$ to 63040 failure cycles.
The results for three different maximum stress models are shown in Figure 26.

1. Hoop stresses due to a power outage and pump restart are the maximum stresses shown (Equation 11, 79575 psi). Note that for any piping conditions, few cycles are required to result in damages. Damages are predicted for a DLF $<4$ or DLF $<2.33$. Also note that, every time that power is interrupted, there is a pressure surge as pumps stop and restart. Pressure surges even occur during momentary outages, but the pressures are limited by the slowing of the pump before it starts back up. Variable frequency drives effectively control pump restart pressures.

2. The next highest stress occurs near Fire Hydrant 2 when it closes, and is about half of the stress caused by a power outage (Equation 10, 39827 psi). Initial failures can occur in as few as 10 cycles, and about half of the pipes are expected to crack in 1000 cycles if there is significant scratching of the surface. Damages are predicted for a $\mathrm{DLF}<3.24$ or DLF $<2.00$.

3. The lowest stresses that were specifically evaluated were for Fire Hydrant 4, which is located away from the closing hydrant (Equation 6, 29363 psi). Note that failures are not expected until about 1000 cycles, unless multiple failure locations are considered. In this case, initial failures can occur at any time. Damages are predicted for a DLF $<4$ but fatigue cracks are not expected DLF $<2.25$, where these fatigue stresses will contribute to cumulative damage when this Hydrant 4 hydrant is closed. Also, "fatigue corrosion" may be an issue at these lower stresses, where this new theory needs further research.

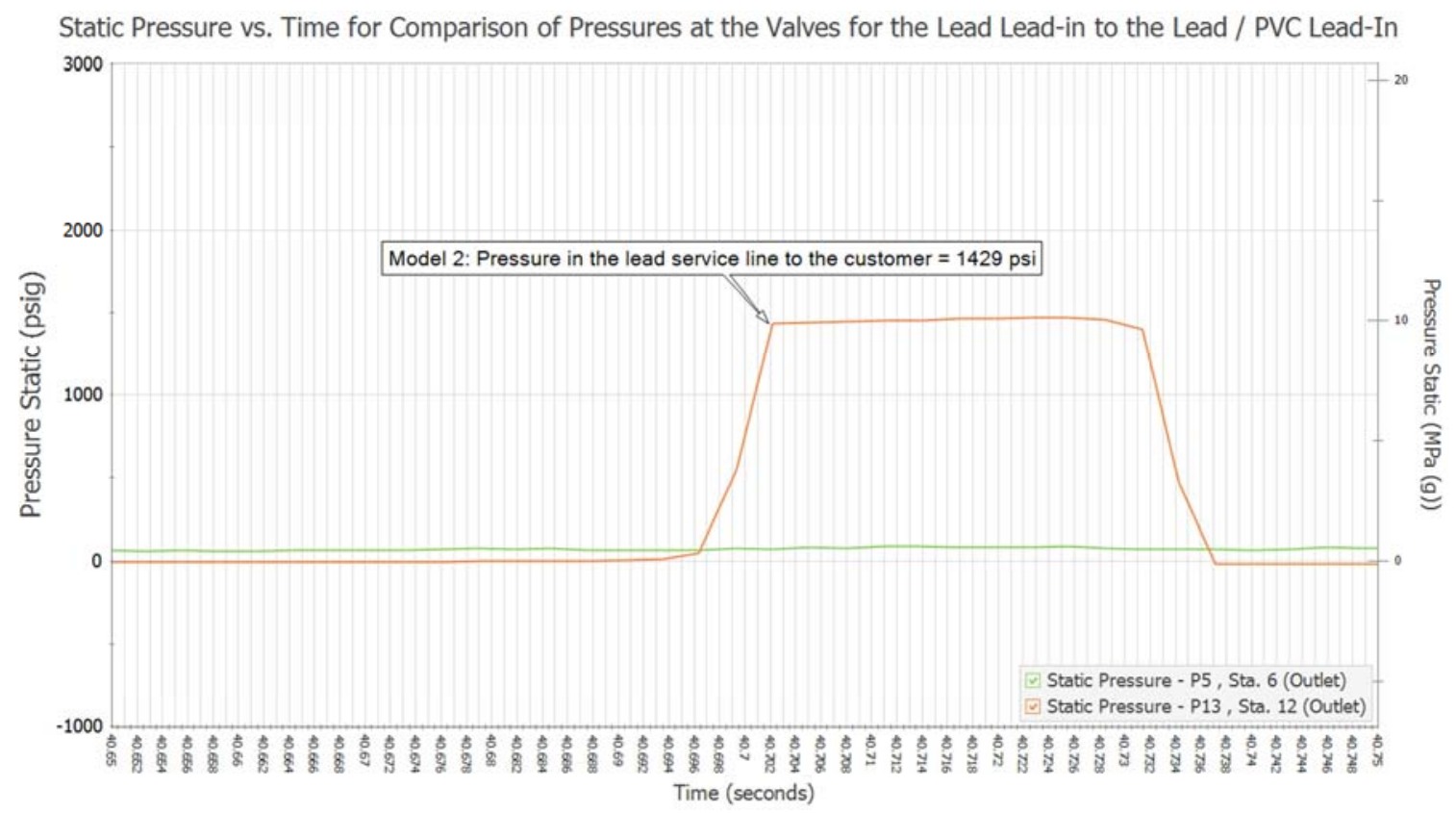

Figure 29. Lead Service Piping Fatigue Evaluation, As Shown In Figure 10. 


\subsubsection{Lead Piping Fatigue Failure Calculations}

Calculations for lead piping differ from steel piping calculations. The fact is that there are no dynamic vibration effects for lead, since the damping is so high that vibrations are overdamped. When lead is struck with a hammer, a thud is heard, while striking steel yields a ringing sound. The sound from a struck object is the same frequency as the vibration frequency of the objet itself. Damping coefficients were calculated using available techniques for metals (Leishear [7]), and the damping coefficient was $2 \cdot 10^{50}$, where damping coefficients between 0 and 1 permit vibration of objects. Any value over 1 overdamps the material to stop vibrations, and damping coefficients of 0 are undamped. That is, the DLF $=1$, and the measured stress is therefore used to directly calculate the hoop stress, such that

$$
\sigma_{\text {dynamic }}=\sigma_{\text {static }}=\frac{P \cdot r}{T}=\frac{1429 p s i \cdot 0.4685}{0.113}=5925 p s i
$$

Limited fatigue data for lead is available, and data is plotted in Figure 28 as published (Manta, et al. [29]). Since fatigue curves are approximately linear on log-log graphs, additional fatigue data points were extrapolated using these data points, the number of cycles can be determined by trial and error to fit the maximum stress to the fatigue curve. To do so, the maximum stress is required as shown in Figure 29.

Using this data lead piping fatigue failures can be better understood. Note that Figure 29 shows that 2000 hammers will crack $50 \%$ of the lead service lines. At first, this estimate seems low, but customer usage provides some insight. Faucets in homes are typically connected to lead pipes using copper or steel tubes, and any hammers that may be initiated from slamming valves will remain in the tubes due to reflected wave effect. In this case, the primary hammers of concern are related to hoses, washing machines, and bath tubs.

Even so, the predicted number of failures still seems low, especially since multiple fatigue failure locations are not considered in Figure 17. Historically, gate valves were used at the time when lead piping was installed, gate valves are turned slowly by design, and water hammers are prevented. As gate valves are replaced by ball valves, hammers begin to crack pipes underground, rather than aboveground as noted in this paper, and the possibility of lead contamination becomes possible. Not only can hammers crack pipes to induce crevice corrosion, but any films on the lead can be cracked as well to induce corrosion. In short, high stresses in lead service pipes induce corrosion to contaminate drinking water. Slow closing of ball valves or the use of gate valves can control such corrosion until lead piping has been replaced.

\subsubsection{Fatigue Calculation Results}

An interesting result is that the fluctuating stresses that are created by water hammer pressure surges lead to a condition where many stress locations create fatigue cracks to magnify the number of fatigue failures. Additionally, the fact that soil contacting the piping induced bounding DLFs to be closer to 4 than 2, which implies that aboveground piping will have DLFs closer to 2 for most water hammers induced by valve closures and pump startups. This observation about DLFs is new to the literature, and this research continues to evolve new understandings of water main failures.

In closing, water hammers were presented here as proof that E. Coli can migrate into water mains during routine operations if there are leaks in the piping. Water main leaks proliferate throughout drinking water supplies, where hundreds of thousands are large enough to be noticed and perhaps millions of smaller leaks go undetected. Models presented here prove that opportunities are available for E. Coli ingress to cause illness and death. For example, Figure 12 shows that negative sub-atmospheric suction pressures occur. Following a power outage or temporarily removing a water main from service.

\section{Conclusions}

This study establishes awareness of newly discovered infection and contamination pathways and preventive actions for consideration, particularly when outbreaks or contaminations are investigated (The Leishear E. Coli Infection and Lead Contamination Theory). A brief discussion of pertinent issues was forwarded to the U.S. Centers for Disease Control and the U.S. Environmental Protection Agency for consideration. That correspondence stated that, "Respectfully, I ask that the following observations be considered. 1) E. coli randomly occurs in soils. 2) There are $[237,600]$ water main breaks in the U.S. every year. 3) Water main breaks are caused by power outages and other causes. 4) Water main breaks provide a path for E. coli to enter the water supply at random cracks in water systems while the power is down. 5) Such contamination will distribute to a home, homes, [farms, ranches] or businesses downstream of the leak location when water mains are re-pressurized. In other words, water main breaks caused by power outages provide a random potential source for E. coli contamination". Additionally, lead and copper contamination of drinking water supplies is accelerated by water hammer.

In short, the goal of this research is to advance technology using new information to change opinions to improve public health. All infections and contaminations cannot be stopped, but infections and contaminations can be carved to a fraction of their current presence in our water supplies.

Numerous examples are also provided here to better understand water main breaks with respect to water hammers (The Leishear Stress Theory for Dynamic Load Factors and the Leishear Water main Break Theory). In general, power outages cause the most damage, and lesser damages are caused by hydrant and valve closures. A new discovery was made during this publication to further explain the extensive scope of the water main break problem. Specifically, water hammer pressure waves induce a fluctuating, wavy vibration pattern into the pipe surface, and this process induces many fatigue failure locations, where each location experiences the same process that occurs when a fatigue tests cracks at a single location. Accordingly, the number of cycles to failure is multiplied by thousands or hundreds of thousands, depending 
on pipe lengths in the city of concern. Corrosion is accelerated in this newly discovered process of "The Leishear Fatigue Corrosion Theory".

Stop water hammers. Stop water main breaks. Reduce annual multi-billion dollar infrastructure costs. Minimize lead and copper contaminations. Stop E. coli ingress. Control E. coli transmissions. Stop E. coli infections. Stop illnesses. Stop fatalities.

\section{References}

[1] Dirk van Elsas J, Semenov AV, Costa R, Trevors JT. Survival of Escherichia Coli in The Environment: Fundamental and Public Health Aspects. ISME Journal. 2011; 5: 173-183 Available at: https://www.nature.com/articles/ismej201080.

[2] New or Repaired Water Mains. United States Environmental Protection Agency, Office of Ground Water and Drinking Water. 2002: 1-13. Available at: https://www.epa.gov/sites/production/files/2015-09/document s/neworrepairedwatermains.pdf.

[3] Leishear RA. Water Hammer Breaks Water Mains. J. Pressure Vessel Technology, American Society of Mechanical Engineers. 2019; $\quad 142 \quad$ (2): $1-18$. https://asmedigitalcollection.asme.org/pressurevesseltech/artic le-abstract/142/2/021402/956268/Water-Hammer-Causes-Wat er-Main-Breaks?redirectedFrom=fulltext.

[4] Leishear RA. Of Course We Can Stop \$1.7 Trillion in Water Main Breaks. Materials Performance, National Association of Corrosion Engineers. 2020: 21-24. Available at: https://nace.mydigitalpublication.com/publication/?m=61416 $\& \mathrm{i}=671084 \& \mathrm{p}=10$.

[5] Reports of E. coli Outbreak Investigations from 2021. United States Environmental Protection Agency. 2021. Accessed March 6, 2021. Available at: https://www.cdc.gov/ecoli/2021-outbreaks.html.

[6] Disinfecting Water Mains, ANSI/AWWA C651-14, American Water Works Association, 2015: 1-26.

[7] Leishear RA, Fluid Transients, Water Hammer, Dynamic Stresses, and Piping Design, American Society of Mechanical Engineers, 2013: 1-444.

[8] E. Coli Symptoms and Cause, Mayo Clinic. https://www.mayoclinic.org/diseases-conditions/e-coli/sympto ms-causes/syc-20372058.

[9] Why the Most Common Cause of UTIs Is E. Coli, Healthline, Available https://www.healthline.com/health/e-coli-uti\#E-coli-and-UTI

[10] Ishii S, Ksoll WB, Hicks RE, Sadowsky MJ, Presence and Growth of Naturalized Escherichia coli in Temperate Soils from Lake Superior Watersheds, Applied and Environmental Microbiology, American Society For Microbiology 2006: 611-621. Available at: https://aem.asm.org/content/72/1/612.

[11] Fox S, Shepherd W, Collin R, Boxall J. Experimental Quantification of Contaminants Ingress Into A Buried Leaking Pipe During Transient Events. Journal of Hydraulic Engineering. 2015: 668-676. Available at: https://ascelibrary.org/doi/pdf/10.1061/\%28ASCE\%29HY.194

\section{3-7900.00010406.}

[12] Yang J, Schneider OD, Jjemba PK, Lechevallier MW, Microbial Risk Modeling for Main Breaks, American Water Works Company, 2015: E97-E108.

[13] Rangel JM, Sparling PH, Crowe, C, Griffin PM, Swerdlow DL. Epidemiology of Escherichia coli O157:H7 Outbreaks, United States. U.S. Centers for Disease Control, 1982-2002. 2005. Available https://wwwnc.cdc.gov/eid/article/11/4/04-0739_article.

[14] Outbreak of E. coli Infections Linked to Ground Beef. United States Environmental Protection Agency. 2019. Accessed March 7, 2021. Available at: https://www.cdc.gov/ecoli/2019/o103-04-19/index.html.

[15] Power Outage in Georgia. Power Outage. Report. Accessed March 7, 2021. Available at: https://poweroutage.report/georgia.

[16] Power Outage in Illinois. Power Outage. Report. Accessed March 7, 2021. Available at: https://poweroutage.report/illinois.

[17] Mora-Rodríguez J, Delgado-Galván X, Ramos HM, López-Jiménez PA, An Overview of Leaks And Intrusion for Different Pipe Materials and Failures, Urban Water Journal, Taylor and Francis Group, 2012: 1-10.

[18] Permeation and Leaching, U.S. Environmental Protection Agency, Office of Water, Office of Ground Water and Drinking Water Distribution System Issue Paper, 2002: 1-22.

[19] Basic Information about Lead in Drinking Water, U.S. Environmental Protection Agency, Available at: https://www.epa.gov/ground-water-and-drinking-water/basic-i nformation-about-lead-drinking-water\#health.

[20] Nathan CC. Corrosion Inhibitors. National Association of Corrosion Engineers. 1973: 114-125. Available at: https://store.nace.org/corrosion-inhibitors.

[21] Principles of the Ethical Practice of Public Health. Public Health Leadership Society. 2002: 1-11. Available at: https://www.apha.org/-/media/files/pdf/membergroups/ethics/e thics_brochure.ashx.

[22] “AFT Impulse 7”, Applied Flow Technology, Boulder Colorado.

[23] "Nuclear Quality Assurance-1 (NQA-1)", U.S. Nuclear Regulatory Commission, Washington, D.C.

[24] "How to Conduct a Single Hydrant Flow Test, Hose Monster University", https://youtu.be/CXr7kceQ2ec.

[25] Dweib AH, 2011, "Acoustic Fatigue Assessment of Piping System Components by Finite Element Analysis," PVP-2011-57371, Pressure Vessel Conference, American Society of Mechanical Engineers, New York, New York.

[26] Beltman W M, Burcsu EN, Shepherd J., Zuhal L, "The Structural Response of Cylindrical Shells to Internal Shock Loading”, 1999, Journal of Pressure Vessel Technology, 121, American Society of Mechanical Engineers, New York, New York.

[27] Templeton D, Ford S, Rodgers A, Harben P, Ramirez A, Foxal, W, Reinke R, "Seismic Models for Near-Surface Explosion Yield Estimation in Alluvium and Sedimentary Rock", 2017, Seismological Society of America, pp. 1-64. 
[28] NTSB, "San Bruno Gas Pipeline Explosion Materials Report" 2011, National Transportation Safety Board, pp. 1-14.

[29] Yakushi, T, Ferguson W, Goto M, "Effect of Water on Ductility and Fatigue Strength of Austempered Ductile Cast Iron (ADI)", 2006, International Journal of Modern Physics, pp. 4571-4576.
[30] Maruta S, Takayama M, Morita K, Yasunaga A, Yanase K, Endo M, "A Study on High Cycle Fatigue Behavior in Lead", 2013, 9th International Conference on Fracture and Strength of Solids, pp. 1-5. 